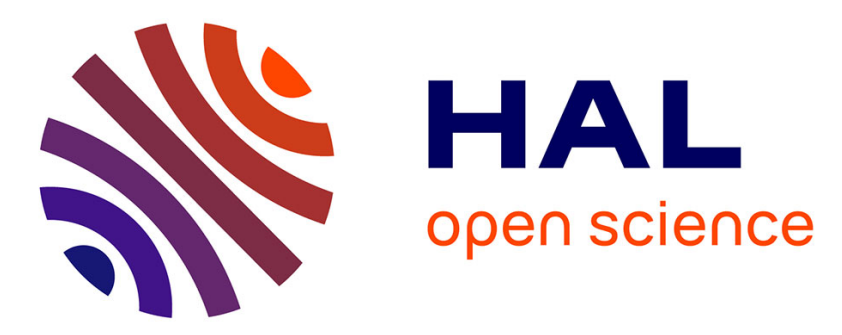

\title{
Early life childcare and later behavioral difficulties: a causal relationship? Data from the French EDEN study
}

Ramchandar Gomajee, Fabienne Elkhoury, Judith van Der Waerden, Laura Pryor, Maria Melchiorthe

\section{- To cite this version:}

Ramchandar Gomajee, Fabienne Elkhoury, Judith van Der Waerden, Laura Pryor, Maria Melchiorthe. Early life childcare and later behavioral difficulties: a causal relationship? Data from the French EDEN study. Journal of Economic Behavior and Organization, 2017, 10.1016/j.jebo.2017.11.027 . hal-01701030

\section{HAL Id: hal-01701030 \\ https://hal.sorbonne-universite.fr/hal-01701030}

Submitted on 7 Feb 2018

HAL is a multi-disciplinary open access archive for the deposit and dissemination of scientific research documents, whether they are published or not. The documents may come from teaching and research institutions in France or abroad, or from public or private research centers.
L'archive ouverte pluridisciplinaire HAL, est destinée au dépôt et à la diffusion de documents scientifiques de niveau recherche, publiés ou non, émanant des établissements d'enseignement et de recherche français ou étrangers, des laboratoires publics ou privés. 


\title{
Early life childcare and later behavioral difficulties: a causal relationship? Data from the French EDEN study
}

\author{
Ramchandar Gomajee, Fabienne ElKhouryJudith van der \\ Waerden, Laura Pryor, Maria Melchiorthe, EDEN mother-child \\ cohort study group
}

\section{INTRODUCTION}

\subsection{Background}

The first years of life are crucial in terms of long-term cognitive and behavioral development (Shonkoff and Richmond, 2009). Therefore, early interventions limiting the impact of adverse environments early on in life may help reduce inequalities in health, cognitive and social development in the short and long-term (Doyle et al., 2009). The most famous research in this area, conducted by James Heckman, shows that the earlier the intervention the higher return on investment and reaped benefits (Carneiro and Heckman, 2003). Childcare prior to school entry varies in type, duration as well as quality. Some children are looked after in their own home, others by relatives or in the home of another caregiver, still others in collective settings with other children. Childcare therefore includes different environments which may have different consequences for children's cognitive and non-cognitive development.

Cognitive development plays a fundamental role with regard to later schooling, income, criminality and success in many facets of social and economic life (Cunha and Heckman, 2010). Over the last 30 years, many studies have therefore studied the influence of early childcare on cognitive development. They have shown that compared to parental care, formal care is associated with increased school readiness, improved receptive vocabulary and better reading skills (Geoffroy et al., 2010; Li et al., 2013) as well as improved language skills 
(Luijk et al., 2015). This may be particularly true for children who come from a disadvantaged socioeconomic background (Geoffroy et al., 2010) or children of immigrants (Dustmann et al., 2012). Long terms benefits of early subsidized childcare include higher educational attainment, labor market participation and reduced welfare dependency especially for individuals from low socioeconomic backgrounds (Havnes and Mogstad, 2011).

Similarly, non-cognitive characteristics including perseverance, self-esteem, self-control and motivation influence educational performance, as well as social and economic success (Borghans et al., 2008; Heckman et al., 2006). There has been much debate regarding the possible role of early life childcare arrangements in potentially increasing or offsetting developmental and behavioral risks. Studies undertaken in the 1980's came to the conclusion that early and extensive non-parental childcare is related to an increased level of disobedience and aggression in children later in life (Baydar and Brooks-Gunn, 1991; Belsky and Rovine, 1988; Haskins, 1985; Rubenstein et al., 1981). Some studies show that children who are in non-parental care have more psychological difficulties than those who stay at home (Belsky et al., 2007; Belsky and Rovine, 1988; Gialamas et al., 2015; McCartney et al., 2010), and the strength of this association appears to be directly related to the number of hours spent out of home (Belsky et al., 2007; Datta Gupta and Simonsen, 2010). Other studies show either no negative impact of childcare on children (Barnes et al., 2010; Beijsterveldt et al., 2005; Gialamas et al., 2014), or even a beneficial effect, especially among children whose mother is depressed or who come from a disadvantaged family (Love et al., 2005; Yamauchi and Leigh, 2011).

Countries in which the impact of childcare arrangements on children's development have been studied vary much in terms of early childhood policies (e.g. affordable access to childcare, parental leave). If the quality of childcare based on UNICEF standards is taken into account (UNICEF Innocenti Research Centre, 2008), studies showing that early childcare is associated with increased levels of behavioral difficulties in children are mostly conducted in countries where the quality of childcare is considered to be low, such as the USA (Belsky et al., 2007; McCartney et al., 2010) and Australia (Gialamas et al., 2015). In studies which take the quality of childcare into consideration, an increase in the level of children's behavioral difficulties was only observed in case of extended hours spent in low quality childcare settings (McCartney et al., 2010), while children spending extended hours in high quality childcare have low levels of behavioral problems (Vandell et al., 2010). 
The interpretation of results in this area can be complicated because different countries have different policies concerning the age of school entry. In most countries children officially start school at the age of six (Canada, Germany, Netherlands, Norway, USA) but in some they start at the age of five (Australia, Ireland, New Zealand, United Kingdom) or seven (Finland, South Africa, Sweden, Switzerland) (UNESCO Institute for Statistics, 2016). The scientific literature on childcare usually refers to care received by children up to the age of school entry. Furthermore, most evaluated interventions in this area were conducted among children from deprived families, and only a few were conducted in countries that have a universal early childcare policy such as the Nordic countries.

In France, the official age for school entry is 6 years. However, 97\% of children aged 3 and 99\% aged 4 attend preschool ("école maternelle") which is free of charge (Blanpain, 2006). Therefore, in France the difference in access to early childcare refers to childcare received before entering preschool, i.e. prior to age three. The French childcare system is based on the principle of universality: public childcare facilities are not aimed at a particular segment of the population but accept everyone irrespective of socioeconomic background (Fagnani, 2012). One of the pillars of the French social protection system, which is largely funded by mandatory employer and employee contributions, is the family policy. The state allocates a budget to the "Caisse Nationale d'Allocations Familiales" (CNAF) (National Office for Family Allowances), which funds and regulates the distribution of subsidies to families as well as the financing of childcare facilities via decentralized "Caisse d'Allocations Familiales" (CAF) (Office of Family Allowances) (Fraisse L et al., 2011). Each municipality, which is the administrative division of a town or a village, has a budget for the development of the territory under its jurisdiction and is free to decide how much money is invested in center-based facilities depending mainly on political orientation, population size and the degree of urbanization. The predominant role of municipalities is to run center-based childcare while the General Council ("le Département”) is responsible for childminder agreements and center-based childcare quality control (Fraisse L et al., 2011).

Center-based childcare and childminders are widely used in France, but the selection generally depends on availability (demand exceeds supply) rather than parents' choice. In center-base childcare facilities, regulations concerning the supervision of children are strict: child-caregiver ratio, timetable of children's activities during the day, ensuring high quality childcare (Collombet, 2012). On the other hand, the quality of childminder's care may vary from one childminder to another, even though they are required to complete mandatory 
training in early child development before being delivered a 5-year renewable permit. Furthermore, there are no pre-established activities (Collombet, 2012) and childminders have a lower level of education when compared to educators in center-based childcare settings (David-Alberola, 2008). Nevertheless, childminders are the main type of out-of-home childcare in France, because the number of places available in center-based childcare is limited (Micheau et al., 2010).

On average, French families spend 411 euro/month on childcare but this amount varies with the type of childcare, the number of hours the child spends in childcare, or and the number of children in the family (Villaume, 2015). Parents pay on a sliding scale according to their income. Through tax deductions and special allowances, childcare is subsidized by the state but can nevertheless be too costly for the most economically disadvantaged families (Fagnani, 2012). Before tax deductions and special allowances, the average cost per month for 35 hours of presence is 334 euro per child for center-based childcare and 625 euro per child for a childminder (Villaume, 2015).

There is a high demand for center-based childcare, especially from middle class families in which both parents are often employed and who view early socialization in a positive way. However, there are often long waiting lists and the demand far exceeds the supply (Fagnani, 2012). The exogenous allocation of places to center-based childcare creates a quasiexperimental situation whereby, among families with young children who wish to have them looked after, the type of childcare (center-based or child-minder) that is allocated does not depend on family characteristics.

In the present investigation, we examine the association between early childcare arrangements, between ages 0 and 3 years, and children's behavior up to age 8 , using data from the longitudinal mother-child EDEN cohort study in France. Most studies assessed whether childcare is associated with behavioral difficulties at one time point or successive time points separately. In the present study we model patterns of behavioral difficulties from age 3 to age 8 using group-based trajectory modeling (Jones et al., 2001). We then compare children's trajectories of behavioral difficulties depending on whether they are in informal vs. formal care and also depending on the type of childcare they are in and its duration.

Additionally, because boys (Chaplin and Aldao, 2013; Miner and Clarke-Stewart, 2008), children whose mother is depressed (Agnafors et al., 2016; Tompson et al., 2010), as well as those who grow up with parents who experience financial difficulties (Barazzetta et al., 2016; 
Miller and Votruba-Drzal, 2016; Rijlaarsdam et al., 2013) are especially prone to behavioral difficulties, we also test whether the type of childcare has a different influence on the behavior of children depending on these characteristics.

\section{METHODS}

\subsection{Study design, setting and participants}

The EDEN mother-child cohort study primary aims to assess pre- and postnatal determinants of child growth, development and health. Recruitment of pregnant women (before 24 weeks of amenorrhea (WA) was conducted in two French university hospitals (Nancy and Poitiers, 2003-2005) during the prenatal visit at the Departments of Obstetrics and Gynecology. Exclusion criteria were: multiple pregnancies, pre-pregnancy diabetes, illiteracy, and plans to move outside the region in the following 3 years. Mothers were examined clinically 3 times: between the $24^{\text {th }}$ and $26^{\text {th }}$ WA, at delivery and 5-6 years after delivery. Self-administered or midwife-administered questionnaires were filled out during the clinical examinations and additionally at 4 months, 8 months, 1 year, 2 years, 3 years, 5.5 years and at 8 years postdelivery (Heude et al., 2016).

Among the 2002 women included in the EDEN cohort, 1,432 participants reported their children's behavioral score in at least one of the 3 possible study waves at 3, 5.5 and 8 years of age, while 1,428 also provided information about childcare between ages 0 and 3 years. These 1,428 mother-child dyads constitute our study population. Compared to the studied population, non-participating mothers are more likely to participate in the Nancy research center (61.4 vs. $47.8 \%$; $\mathrm{p}<0.0001)$, to be younger (mean age $=28.2$ years, $\mathrm{SD}=5.1$ years vs. 29.9 years, $\mathrm{SD}=4.7$ years; $\mathrm{p}<0.0001$ ), have lower education (mean number of years of education $=12.4$ years, $\mathrm{SD}=2.3$ years vs. 13.6 years, $\mathrm{SD}=2.3$ years; $\mathrm{p}<0.0001$ ), smoke cigarettes before pregnancy (49.4 vs. $32.3 \%$; p<0.0001), less likely to be employed (63.9\% vs. $81.5 \%$; $\mathrm{p}<0.0001)$, less likely to receive social support $(62.5$ vs. $71.4 \% ; \mathrm{p}=0.0002)$ and more likely to have a history of mental health problems (21.8 vs. $14.0 \%$; $\mathrm{p}<0.0001)$. Participating children, as compared to non-participants, were less likely to be first-born (38.9 vs. $46.5 \%$; $\mathrm{p}=0.0047$ ) and more likely to be born with a low birth-weight (7.3 vs. $4.8 \%$; $\mathrm{p}=0.0352$ ).

\subsection{Variables}




\subsubsection{Childcare}

From the age of 4 months to 3 years, age at which children generally enter preschool in France, mothers were asked to report the type of childcare primarily used by their child (crèche/daycare, day nursery, childminder, relatives, neighbors and friends, a babysitter or whether the parents looked after the child themselves).

Childcare type was then divided into 3 groups:

1. Childminder, $C M(N=636,45.6 \%)$ : a professional caregiver with a formal degree in early childhood education, with a 5-year renewable permit allowing her to take care of up to 6 children in her own house.

2. Center-based childcare, $C B C(N=367,25.7 \%)$ : school-like structures such as crèches, daycare, center-based cribs and day nurseries with professional caregivers.

3. Informal childcare, IC $(\boldsymbol{N}=\mathbf{4 2 5}, \mathbf{2 9 . 8 \%})$ : parental care only $(71.3 \%, \mathrm{n}=303)$ or parental care combined with other non-professional caregivers (e.g. grand-parents, aunts and uncles, friends) $(28.7 \%, \mathrm{n}=122)$ grouped together because of shared characteristics.

If the child attended center-based care at any one point in time, she/he was included in the 'center-based' group; if the child never attended center-based care but with a childminder at any one point in time she/he was classified in the latter group. If the child was neither in center-based care nor with a childminder, she/he was allotted to the informal care group. The 3 groups are mutually exclusive ${ }^{1}$.

Furthermore, by taking into account the type of childcare in the successive waves of questionnaires from 4 months to 2 years, we were able to divide children who were in center-

\footnotetext{
${ }^{1}$ All children belonged to only one of the groups. In fact, very few children either switched from a childminder's care to center-based childcare or vice-versa (25) or were in both types simultaneously (19). Children stayed in informal care (mostly parental care) until they attended center-based or a childminder. Therefore, children who were never in either childminder's care or center-based care were in the "informal care" group; those who were never in center-based but had been in a childminder's care were in the "childminder" group and all those who had experienced center-based childcare at any point in the study were in the "center-based childcare" group. Thus children who experienced both childminder's care and center-based care were classified in the latter group (this situation concerns only a small percentage of all children). There are two main reasons behind this classification. Firstly, we assumed that center-based childcare would have the greatest effect on children, positive or negative. Secondly, in France center-based childcare is highly regarded by parents and some parents put their child in childminder's care while they are on a waiting list for a place in a center-based childcare. In this case the child may spent a few weeks with a childminder before entering center-based childcare.

Hence, even the 5 groups based on type and duration of childcare which we studied were mutually exclusive. A child who spent 3 months with a child-minder before entering center-based care for 2 years is classified only in the group 'center-based childcare for at least one year'.
} 
based and childminder groups into 2 more groups each, depending on the total time spent in care:

1. Childminder $<1$ year,

2. Childminder $>=1$ year,

3. Center-based care $<1$ year,

4. Center-based care $>=1$ year

5. Informal care.

\subsubsection{Childhood behavioral difficulties: SDQ score}

The French version of the Strength and Difficulty Questionnaire (SDQ) was used to measure children's behavior at ages 3, 5.5 and 8 years. Translated into several languages, the SDQ is a validated screening instrument for emotional and behavioral problems in children and adolescents from 3 years of age onwards (Algorta et al., 2016; Goodman, 1997; Shojaei et al., 2008).

It contains 25 items divided into 5 scales of 5 items each: one positive scale (pro-social behavior) and four negative scales (emotional symptoms, behavior/conduct problems, hyperactivity/inattention, and peer relationship problems). Each scale is scored from 0 to 10 . The 4 negative scales are summed to calculate the total SDQ score, which ranges from 0 to 40 (Youthinmind, 2015).

\subsubsection{Covariates}

Covariates include variables potentially associated either with the type of childcare or children's behavioral difficulties. Only measures obtained between baseline and age 3 years, which is the age when children in France enter preschool, were considered.

Among these variables were participants' socio-demographic characteristics: study center (Nancy or Poitiers); family situation (married/cohabiting or single); mother's age at delivery; parents' education level (number of years of education dichotomized at 14 years, which is equivalent to the French High School Certificate (baccalauréat) +2 years of higher education); parents' employment status at each study wave; and the presence of financial difficulties (difficulties to buy food or clothes for the family, difficulties to pay the rent, 
heating or electricity, regular overdraft of bank account, subsidized health coverage, a family income of less than 1500 euros at least once during the study period).

Maternal psychological difficulties: The Centre for Epidemiological Studies Depression (CESD) questionnaire was used to detect mother's depressive symptoms at 24 weeks of amenorrhea (Radloff, 1977). To identify individuals at risk of clinical depression, the score was cut-off at 23 or above (Fuhrer and Rouillon, 1989). The Edinburgh Postnatal Depression Scale (EPDS), a 10- item questionnaire devised to identify postnatal depression was used during the first year after birth (4, 8 and 12 months) to screen for the mothers' depression symptoms, with a score ranging from 0 to 30 (Cox et al., 1987). A threshold score of 13 or above was used to identify women at risk of clinical depression (Matthey et al., 2006).

Other variables pertaining to the mothers' psychological status include the use of psychological help during pregnancy and after birth (e.g. anxiolytics, sleeping pills, counselling) and self-reported mental health problems prior to pregnancy.

Other variables include parents' own behavioral difficulties during childhood, parents' use of psychoactive drugs (alcohol, cigarettes, cannabis), and the frequency of different parent-child activities (e.g. reading a story, feeding, playing, bathing, etc.).

\subsection{Statistical methods}

\subsubsection{Mean SDQ score}

We tested whether there was a significant difference in behavioral symptoms across the different childcare groups by comparing mean SDQ scores: (i) children in formal vs. informal childcare; (ii) children with a childminder or in informal care vs. those in center-based childcare.

\subsubsection{Group-based trajectory modelling - Behavioral trajectories}

Using data from participants with at least one of the three SDQ measures, we estimated participating children's behavioral trajectories with group-based trajectory models (Jones et al., 2001; Nagin and Land, 1993; Nagin and Tremblay, 2005). This semi-parametric modeling procedure enables the identification of clusters of individuals who follow a similar 
developmental trajectory of a variable of interest (Nagin and Odgers, 2010), in this case overall behavioral scores.

Unlike hierarchical modeling and latent curve analysis which assume that the population of trajectories varies continuously across individuals and in a fashion that can be explained by a multivariate normal distribution of population parameters, group-based trajectory modeling assumes that there may be distinctive developmental trajectories that reflect distinct etiologies (Nagin, 2005). Furthermore, the definition of groups is based on formal statistical modeling rather than subjective classification rules and can be verified by testing the posterior probability of group membership (Nagin, 2005).

The method considers that data are missing at random (Broadbent et al., 2008) and individuals with missing data are assigned to their most likely group.

Several models were tested examining an increasing number of developmental trajectories and different shapes (linear, quadratic, cubic) - the best model was determined using the Bayesian Information Criterion (BIC) (Jones et al., 2001; Jones and Nagin, 2007; Nagin and Odgers, 2010) and maximizing the probability of group membership (>=0.7 ) (Nagin, 2005; Nagin and Odgers, 2010).

\subsubsection{Multiple Data Imputation}

Complete case analysis, i.e. the analysis of subjects with no missing data may lead to the exclusion of large numbers of participants especially when examining measures repeated over time. It may also sometimes result in biased results (Sterne et al., 2009). One approach to deal with missing data is multiple imputation (MI). MI does not seek to replace a missing value with a simulated one but rather produces a random sample of possible values that represent the unpredictability of the missing value (Yuan, n.d.). MI involves 3 steps:

1. Multiple copies of the dataset are created with missing values filled in by imputed values based on a Bayesian approach (Sterne et al., 2009).

2. Standard procedures are used to analyze the different datasets producing different estimated associations and reflecting the uncertainty associated with the imputed missing values.

3. The results are combined to draw an inference. 
Only covariates were imputed. We assume that data were missing at random, i.e. the probability of a variable being missing depends on observed variables but not on the value of the missing variable. A wide range of variables predictive of missing data were included in the imputation model, even if they did not form part of the substantive analyses (Sterne et al., 2009).

Full Conditional Specification (FCS) Multiple Imputation with 10 imputations of each missing value was used. FCS MI is flexible and allows the specification of a model for each type of variable, e.g. linear regression for continuous variables, logistic regression for binary variables (Bartlett et al., 2015).

PROC MIANALYZE in SAS V9.4 was then used to combine results when analyzing the complete imputed dataset.

\subsubsection{Inverse Probability Treatment Weights (IPW) adjusted analyses}

One of the issues in examining the relationship between childcare type and children's development using observational data is that children who attend childcare differ from those who do not (e.g. high socioeconomic position, positive interactions with parents).

A propensity score (PS) is the probability of treatment assignment conditional on observed baseline covariates $(\mathrm{Z}=$ the indicator for the observed treatment exposure, $\mathrm{X}=$ the vector of covariates)(Austin, 2011; Rosenbaum and Rubin, 1983):

$$
\mathrm{e}(\mathrm{X})=\mathrm{P}(\mathrm{Z}=1 \mid \mathrm{X}), 0<\mathrm{e}(\mathrm{X})<1
$$

It is a covariate summary score. Subjects having the same PS, whether they are treated (exposed) or not, have, on average, the same distribution of covariates used to estimate the PS. Therefore, individuals with the same propensity score share a similar distribution of $\mathrm{X}$ regardless of their treatment exposure.

Several methods have been used to reduce selection bias by using PS: covariate adjustment, matching, stratification and Inverse Probability Weight of treatment (IPW)(Austin, 2011; Xu et al., 2010). In our study we calculated propensity scores for each subject and used the Inverse Probability Weight of treatment to account for selection bias. In IPWs, each observation is weighted by the reciprocal of the predicted probability of receiving the treatment that was observed for each patient, which can be estimated using propensity scoring. "With the appropriate weights, the weighted study population will be balanced across 
the treatment groups on the confounding factors. This balance is what allows for unbiased estimates of treatment effects in randomized controlled trials, thus IPW can be thought of as simulating randomization in observational studies"(Crowson et al., 2013).

By using the inverse probability of treatment received to weigh the subjects, an artificial sample is created whereby treatment selection is independent of measured baseline covariates, making it possible to measure average treatment effects (Austin and Stuart, 2015). In the synthetic sample created after PS are calculated and IPW applied, the treated and untreated population will have similar baseline characteristics, the main difference between the two groups being the treatment.

The IPW are calculated from the PS and are applied only once in the model. They are used to balance covariates between the 3 childcare groups but do not modify the treatment exposure or outcomes. The IPW procedure serves to make counterfactual inference. Individuals with a high probability of being treated that are actually treated bring no counterfactual information whereas individuals with a low probability of receiving treatment who actually receive treatment are much more informative on treatment effects. Similarly for individuals with a high probability of being exposed who actually are not exposed are more informative.

Multinomial multivariate logistic regression was used to calculate the probability of being in each childcare group and hence the PS (Crowson et al., 2013). Variables related to the outcome were included in the model for calculating propensity scores (Austin et al., 2007; Austin, 2011; Brookhart et al., 2013). We made sure that PS distributions in the different childcare groups overlapped (Lanehart et al., 2012) (supplementary figure 1).

Weights were stabilized by dividing by the mean weight in order to minimize extreme weights and reduce type 1 error and weights above the $99^{\text {th }}$ percentile were curtailed to the $99^{\text {th }}$ percentile before verifying that the stabilized mean weight was close to 1 . With IPWs, each observation is weighted by the inverse of the PS. Extreme weights may result from observations with a PS close to 1 or 0 and consequently result in rejecting the null hypothesis too frequently (Xu et al., 2010). Finally, we verified that confounding factors were more evenly distributed among the 3 childcare groups post- than pre-weighing (supplementary Table 2) (Austin and Stuart, 2015; Lanehart et al., 2012). Multinomial logistic regression models were used to analyze whether childcare type predicted children's SDQ score trajectory group (intermediate or high, vs. low group). 


\subsubsection{Interactions}

We tested for statistical interactions and performed stratified analyses to test whether the effect of childcare varied with the child's gender, maternal depression during the perinatal period, maternal education or low family income (income $<1500$ euros) between pregnancy and the child's 3-year assessment. To maximize the statistical power of these analyses, we combined children with intermediate and high trajectories of behavioral or emotional difficulties yielding a binary outcome: low vs. intermediate/high SDQ score trajectory.

\section{RESULTS}

\subsection{Descriptive analysis}

Table 1 shows children's and families' characteristics depending on the type of childcare between ages 0 and 3 years (childminder: $44.5 \%, \mathrm{~N}=636$; center-based care: $25.7 \%, \mathrm{~N}=$ 367 ; informal care: $29.8 \%, \mathrm{~N}=425$ ). The average proportion of missing values among covariates was $6.4 \%$. All the covariates had less than $20 \%$ of missing values except the mother's EPDS score at 12 months (22.2\%). Overall, children who were in out-of-home care came from families with higher levels of education and employment, and lower levels of financial difficulties and parental mental health problems than those who were in informal care. We observed relatively few differences with regard to these baseline characteristics between children who were cared for by a child-minder and those who were in center-based care. In terms of trajectories of behavioral difficulties, children in the informal childcare group had the highest SDQ score levels, those in center-based care the lowest.

\subsection{Behavioral and emotional symptoms levels}

Table 2 shows the mean SDQ scores at 3, 5.5 and 8 years across the different childcare groups when compared successively to the informal group and the center-based childcare group. Children in informal care had the highest mean SDQ scores in each of the three periods while those in center-based had the lowest.

\subsection{Behavioral and emotional trajectories}

The final model for group-based trajectories consisted of 3 distinct groups (Figure 1): a low SDQ score trajectory $(50.4 \%, \mathrm{n}=721$ ) (low symptoms throughout), an intermediate SDQ score trajectory $(40.2 \%, \mathrm{n}=574)$ and a high SDQ score trajectory $(9.3 \%, \mathrm{n}=133$ ) (high 
symptoms throughout). The 3 trajectories were somewhat flat and parallel showing that children with a comparatively high level of behavioral or emotional symptoms at 3 years also had high levels at 5.5 and 8 years.

Children's mean probabilities of being in each respective trajectory group were $0.78(\mathrm{SD}=$ $0.14)$ for the low trajectory, $0.84(\mathrm{SD}=0.14)$ for the intermediate trajectory and $0.76(\mathrm{SD}=$ 0.16) for the high trajectory. We used the low trajectory group as the reference. Mean SDQ scores in the low, intermediate and high trajectory groups were respectively: 6.70 (SD = $2.81), 12.18(\mathrm{SD}=3.15)$ and $17.91(\mathrm{SD}=4.07)$ at 3.5 years; $5.10(\mathrm{SD}=2.61), 11.06(\mathrm{SD}=$ $3.06)$ and $18.60(\mathrm{SD}=4.18)$ at 5.5 years and $5.14(\mathrm{SD}=2.72), 11.08(\mathrm{SD}=3.42)$ and 18.07 $(\mathrm{SD}=4.13)$ at 8 years.

\subsection{Bivariate analysis}

In bivariate analyses, children who were looked after by a childminder or in informal care had higher levels of emotional and behavioral difficulties than those who were in center-based childcare, and children looked after by a childminder's care had lower levels than those in informal care (Table 3a).

Examining the time spent in childcare (Table 3b), we observed that compared to children who spent at least 1 year in center-based childcare, those who were in a childminder's care, irrespective of the time spent, as well as those who were in informal care were more likely to be in the high or intermediate trajectories of behavioral problems.

\subsection{IPW-adjusted analysis}

In IPW-adjusted multivariate analyses, the ORs associated with childcare attendance decreased and lost statistical significance (Table 4a).

However, compared to children who were in center-based childcare for at least one year $(14.0 \%, \mathrm{~N}=200)$, those who spent less than 1 year in a childminder's care $(12.2 \% ; \mathrm{N}=174)$ and those in informal care $(29.8 \%, \mathrm{~N}=425)$ had a higher likelihood of being in the intermediate and high trajectories of total difficulties while those who spent at least 1 year in a childminder's care $(32.4 \% ; \mathrm{N}=462)$ or less than 1 year in center-based childcare $(11.7 \% ; \mathrm{N}$ $=167$ ) were associated with the high trajectory of behavioral difficulties (Table $\mathbf{4 b}$ ).

\subsection{Subgroup analyses}


Table 5 shows the results of subgroup analyses in which trajectories that correspond to intermediate and high symptom levels of behavioral difficulties were merged and compared with the low symptom trajectory.

\subsubsection{Gender}

In comparison to girls who were in informal childcare $(28.3 \%, \mathrm{~N}=194)$, girls who were looked after by a childminder $(43.9 \%, \mathrm{~N}=301)$ had a decreased likelihood of having a high trajectory of emotional or behavioral difficulties as did those who were in center-based childcare $(27.7 \%, \mathrm{~N}=190)$, although the latter result did not reach statistical significance.

Spending more than 1 year in a childminder's care $(31.4 \%, \mathrm{~N}=215)$ or in center-based childcare $(15.9 \%, \mathrm{~N}=109)$ was associated with a decreased likelihood of having a higher trajectory of behavioral difficulties when compared to informal care while informal care. Girls looked after by a childminder for less than 1 year was associated with an increased likelihood of high level behavioral difficulties compared to girls who spent more than 1 year in centerbased childcare.

Compared to boys in informal care, those in a childminder's care $(45.1 \%, \mathrm{~N}=355)$, especially for less than 1 year $(11.8 \%, \mathrm{~N}=88)$, had a higher likelihood of high behavioral difficulties.

\subsubsection{Mother's education level}

Among children whose mother had a high educational level $(\mathrm{N}=840)$, compared to those who spent at least 1 year in center-based childcare, those who were in a childminder's care for less than 1 year and those who were in informal care had higher levels of behavioral symptoms. On the other hand, among children whose mother had a low educational level $(\mathrm{N}=$ 588), only a childminder's care for less than 1 year was significantly associated to a higher trajectory of behavioral problems when compared to center-based childcare for at least 1 year.

\subsubsection{Mother's depression status}

Overall, there was no significant association between childcare type or time spent in childcare and behavioral trajectories for children whose mother was depressed during the perinatal period $(23.9 \%, \mathrm{~N}=343)$. To the contrary, among children whose mother did not have depression $(76.1 \%, \mathrm{~N}=1085)$, compared to those who were in center-based childcare for at least 1 year, those who were in informal childcare or in a childminder's care for less than 1 year were more likely to have a higher trajectory of behavioral difficulties. 


\subsubsection{Low income}

Overall, we found no evidence that children growing up in low income families gained from being in childcare between ages 0 to 3 . However, among families who had intermediate/high income ( $\mathrm{N}=1159$ ), compared to children were in center-based childcare, those who were in informal childcare or in a childminder's care were more likely to be in a trajectory of high emotional or behavioral difficulties.

\section{DISCUSSION}

\subsection{Main findings}

Using data from 1428 mother-child dyads participating in the EDEN mother-child cohort, we identified three trajectories of children's emotional and behavioral difficulties from ages 3 to 8: low (50.4\%), intermediate (40.2\%) and high (9.3\%).

In bivariate analyses, children who were looked after by a childminder or who were in centerbased childcare were less likely to have intermediate or high levels of emotional or behavioral difficulties up to age 8 years. However, after taking into account a large number of sociodemographic, parental and child characteristics, we did not observe statistically significant differences between the three childcare groups. Nevertheless, when children who spent at least 1 year in center-based care were compared to children in other settings, we found that those in informal childcare as well as those who were in a childminder's care, irrespective of the time spent there, were more likely to have intermediate or high levels of behavioral difficulties.

Secondary analyses showed that levels of emotional or behavioral difficulties were generally lowest among children who were in center-based childcare, particularly if they stayed there for more than 1 year. Girls were more likely to benefit from formal childcare. There were no significant differences in levels of behavioral difficulties for boys who were in informal care or center-based childcare, but child-minders' care, especially for a duration of less than 1 year was associated with higher levels of behavioral difficulties symptoms. In the context of debates about the role of early childcare with regard to children's behavioral development, our study indicates that center-based childcare attendance in France does not cause children's psychological difficulties and may even have a protective effect.

\subsection{Strengths and limitations}


Our study has several strengths. First, we used a prospective design which allowed us to ascertain study exposure and outcome as well as multiple covariates prospectively, between the time of the child's birth to school entry, yielding rich information on children's situation, behavior as well as their family context. Second, we used group-based trajectory modeling of children's SDQ scores to define developmentally sound groups in a more precise way using a single measure. Third, we used propensity scores and inverse probability weights (IPW) to account for selection factors and confounders. Studies showed that in the case of fewer than eight classes per confounder, and with several confounders, analyses based on propensity scores yield estimates that are less biased, more robust, and more precise than a logistic regression based approach (Cepeda et al., 2003). Third, given the specific context prevailing in France, we were able to directly compare two groups that are quite similar in terms of background characteristics yet imply different educational content: childminder vs. centerbased childcare. This situation strengthens our ability to draw causal inferences from our findings.

However, we also acknowledge limitations. First, the EDEN study is not representative of children in France. Indeed, the study was set up in two cities and, as in other cohort studies, participants were selected. However, the sample we studied is heterogeneous from the point of view of family background characteristics and levels of childcare attendance are comparable to national estimates. Second, our measure of early childcare may be relatively rough. Indeed, children can change childcare type during the 3 years before they enter school and it may be that childcare transitions are relevant with regard to later development. However, though transitions from informal childcare to formal childcare are frequent, especially during the first year of life, once a child is in a formal childcare type he/she generally does not go back to informal care. In our study, 25 children either moved from center-based childcare to a childminder or vice-versa while 19 children attended both types of formal childcare simultaneously at least once during the study period. Third, children's behavior was ascertained by their mothers, and may be sensitive to reporting bias. Nevertheless, mothers are generally reliable in assessing their children's behavior in middle childhood (Mieloo et al., 2012) and our longitudinal measure is more valid than a single ascertainment at one point in time.

\subsection{Possible mechanisms linking early childcare to children's behavior}

In the context of controversy regarding the consequences of early childcare, our findings are in line with data from the NICHD Early Child Care Research Network study (The NICHD 
Early Child Care Research, 1998) as well as a large Norwegian cohort study ( $\mathrm{N}=75,271)$ (Zachrisson et al., 2013) which showed that early, extensive and continuous childcare was not related to an increased likelihood of childhood behavioral problems. In fact, quality nonparental care was reported to be positively associated to children's social capabilities and behavior (The NICHD Early Child Care Research, 1998). However, in the first study only a small percentage of center-based childcare settings could be classified as 'good quality'; e.g. only $36 \%$ of centers had enough caregivers at 6 months, $20 \%$ at 15 months and $26 \%$ at 24 months (The NICHD Early Child Care Research, 1998). In Norway, on the other hand, childcare quality as high as in France (UNICEF Innocenti Research Centre, 2008) and very widespread (97\% of children attend) (Zachrisson et al., 2013). Our findings extend this prior knowledge by showing that center-based childcare may be especially beneficial if children attend for at least one year.

Our results can be explained by several mechanisms. First, children who attend childcare differ from those who stay at home until preschool entry with regard to many characteristics including family socioeconomic factors and parental history of mental health problems which can both influence children's behavioral development. While this is the case in our study as in other settings, we were able to control for multiple family background characteristics and compare children who were in childminder care with children who attended a center-based childcare setting, which reduces the influence of this type of bias. Second, center-based care enables children's early socialization and respect of societal rules (Bernal and Fernández, 2013). Exposure to positive stimulation through praise, play and reading (Klasen and Crombag, 2013) can have long-term beneficial consequences on brain, neuroendocrine, cognitive or psychosocial development (Wachs et al., 2014). Fewer symptoms of depression and social inhibition as well as reduced violent behaviors have been observed among children who are stimulated from a young age onwards (Walker et al., 2011). This type of stimulation in a formal setting may also favor children's cognitive development, with, in the long term, better general knowledge, academic achievement, and higher IQ. This may explain why some studies have shown that center-based childcare is especially beneficial children growing up in disadvantaged families (Geoffroy et al., 2010; Love et al., 2005). In our study, we did not find evidence of such an effect, and to the contrary, children who did not experience hardship were those who were most likely to benefit from being in childcare. It may be that the universal approach which is applied in French early education programs does not suffice to help children overcome the difficulties that can result from deficits in early life stimulation and 
caretaking. However, it has to be noted that our sample is not representative of children in France, and additional research using nationally representative data will need to verify this hypothesis. Overall, we observed that at least one year spent in childcare was necessary to observe protective effects, which will also need to be verified using nationally representative data.

\subsection{Social and economic policies}

In 2013, France spent approximately $1.3 \%$ of its GDP on provision of childcare and preprimary education. Comparatively, the USA spent around $0.4 \%$, Norway $1.3 \%$ and Iceland $1.8 \%$ (OECD average: approximately $0.8 \%)(\mathrm{OECD}, 2016)$. However, while public policies in the 1980s aimed to provide childcare facilities so that mothers could work, policies launched in the 1990's created the 'allocation parentale d'éducation (APE)', a financial aid for mothers who wish to stop working in order to take care of their children. This benefit is mainly used by women who are employed in low-wage jobs(Fagnani, 2006). Overall, in 2010, formal childcare use was used by less than $20 \%$ of families in the lowest income quintile, and $60 \%$ of families in the two highest income quintiles(Mills et al., 2014). Our results, along with other studies showing positive influences of center-based childcare on children's cognitive development, suggest that public policies should aim to give access to high quality centerbased childcare to a higher proportion of children under the age of 3 years (Choné et al., 2003).

Our study shows that center-based childcare in a country were childcare is strictly regulated, subsidized and of high quality has a positive impact on children's psychological development. The impact of childminder's care, on the other hand, is more equivocal. This implies that public policies that increase access to high quality center-based childcare are most likely to have a positive role on children's long-term psychological development. Further studies are necessary to find out ways in which boys, as well as children whose mother is depressed or who grow up in low-income families can attend childcare in higher proportions and fully benefit from it.

\section{$\underline{\text { Acknowledgements }}$}

Funding: The EDEN cohort study was supported by Foundation for Medical Research (FRM), National Agency for Research (ANR), National Institute for Research in Public 
Health (IRESP: TGIR cohorte santé 2008 program), French Ministry of Health (DGS), French Ministry of Research, Inserm Bone and Joint Diseases National Research (PRO-A) and Human Nutrition National Research Programs, Paris-Sud University, Nestlé, French National Institute for Population Health Surveillance (InVS), French National Institute for Health Education (INPES), the European Union FP7 programmes (FP7/2007-2013, HELIX, ESCAPE, ENRIECO, Medall projects), Diabetes National Research Program (through a collaboration with the French Association of Diabetic Patients (AFD)), French Agency for Environmental Health Safety (now ANSES), Mutuelle Générale de l'Education Nationale (MGEN), French National Agency for Food Security, and the French-speaking association for the study of diabetes and metabolism (ALFEDIAM). The funders had no role in design and conduct of the study; collection, management, analysis, and interpretation of the data; preparation, review, and approval of the manuscript; or the decision to submit the manuscript for publication.

Competing interests: All authors declare no support from any organization for the submitted work, no financial relationships with any organizations that might have an interest in the submitted work, no other relationships or activities that could appear to have influenced the submitted work.

Ethical approval: All cohort participants signed a written informed consent at enrolment. Further details on the study can be found on the EDEN website: http://eden.vjf.inserm.fr/index.php/en/ 


\section{References}

Agnafors, S., Sydsjö, G., Comasco, E., Bladh, M., Oreland, L., Svedin, C.G., 2016. Early predictors of behavioural problems in pre-schoolers - a longitudinal study of constitutional and environmental main and interaction effects. BMC Pediatr. 16, 76. https://doi.org/10.1186/s12887-016-0614-x

Algorta, G.P., Dodd, A.L., Stringaris, A., Youngstrom, E.A., 2016. Diagnostic efficiency of the SDQ for parents to identify ADHD in the UK: a ROC analysis. Eur. Child Adolesc. Psychiatry 1-9. https://doi.org/10.1007/s00787-015-0815-0

Austin, P.C., 2011. An Introduction to Propensity Score Methods for Reducing the Effects of Confounding in Observational Studies. Multivar. Behav. Res. 46, 399-424. https://doi.org/10.1080/00273171.2011.568786

Austin, P.C., Grootendorst, P., Anderson, G.M., 2007. A comparison of the ability of different propensity score models to balance measured variables between treated and untreated subjects: a Monte Carlo study. Stat. Med. 26, 734-753. https://doi.org/10.1002/sim.2580

Austin, P.C., Stuart, E.A., 2015. Moving towards best practice when using inverse probability of treatment weighting (IPTW) using the propensity score to estimate causal treatment effects in observational studies. Stat. Med. 34, 3661-3679. https://doi.org/10.1002/sim.6607

Barazzetta, M., Clark, A.E., D’Ambrosio, C., 2016. Childhood Circumstances and Young Adulthood Outcomes: The Effects of Mothers' Financial Problems [WWW Document]. URL http://www.fas.nus.edu.sg/ecs/events/seminar/seminar-papers/1611-04.pdf (accessed 7.12.17).

Barnes, J., Leach, P., Malmberg, L.-E., Stein, A., Sylva, K., the FCCC Team, 2010. Experiences of childcare in England and socio-emotional development at 36 months. Early Child Dev. Care 180, 1215-1229. https://doi.org/10.1080/03004430902943959

Bartlett, J.W., Seaman, S.R., White, I.R., Carpenter, J.R., 2015. Multiple imputation of covariates by fully conditional specification: Accommodating the substantive model. Stat. Methods Med. Res. 24, 462-487. https://doi.org/10.1177/0962280214521348

Baydar, N., Brooks-Gunn, J., 1991. Effects of maternal employment and child-care arrangements on preschoolers' cognitive and behavioral outcomes: Evidence from the Children of the National Longitudinal Survey of Youth. Dev. Psychol. 27, 932-945. https://doi.org/10.1037/0012-1649.27.6.932

Beijsterveldt, T.C.E.M.V., Hudziak, J.J., Boomsma, D.I., 2005. Short- and Long-Term Effects of Child Care on Problem Behaviors in a Dutch Sample of Twins. Twin Res. Hum. Genet. 8, 250-258. https://doi.org/10.1375/twin.8.3.250

Belsky, J., Rovine, M.J., 1988. Nonmaternal Care in the First Year of Life and the Security of Infant-Parent Attachment. Child Dev. 59, 157-167. https://doi.org/10.2307/1130397

Belsky, J., Vandell, D.L., Burchinal, M., Clarke-Stewart, K.A., McCartney, K., Owen, M.T., The NICHD Early Child Care Research Network, 2007. Are There Long-Term Effects of Early Child Care? Child Dev. 78, 681-701. https://doi.org/10.1111/j.14678624.2007.01021.x

Bernal, R., Fernández, C., 2013. Subsidized childcare and child development in Colombia: Effects of Hogares Comunitarios de Bienestar as a function of timing and length of $\begin{array}{lllll}\text { exposure. Soc. } & \text { Sci. }\end{array}$ https://doi.org/10.1016/j.socscimed.2012.10.029

Blanpain, N., 2006. Scolarisation et modes de garde des enfants âgés de 2 à 6 ans. DREES, Études et Résultats, $\mathrm{n}^{\circ}$ 497. [WWW Document]. URL 
http://www.lalettredeleducation.fr/IMG/pdf/tudes_et_resultats_no497_juin_2006.pdf (accessed 2.7.17).

Borghans, L., Duckworth, A.L., Heckman, J.J., Weel, B. ter, 2008. The Economics and Psychology of Personality Traits. J. Hum. Resour. 43, 972-1059. https://doi.org/10.3368/jhr.43.4.972

Broadbent, J.M., Thomson, W.M., Poulton, R., 2008. Trajectory Patterns of Dental Caries Experience in the Permanent Dentition to the Fourth Decade of Life. J. Dent. Res. 87, 69-72.

Brookhart, M.A., Wyss, R., Layton, J.B., Stürmer, T., 2013. Propensity Score Methods for Confounding Control in Nonexperimental Research. Circ. Cardiovasc. Qual. Outcomes 6, 604-611. https://doi.org/10.1161/CIRCOUTCOMES.113.000359

Carneiro, P., Heckman, J.J., 2003. Human capital policy. Natl. Bur. Econ. Res. NBER Working Paper 9495.

Cepeda, M.S., Boston, R., Farrar, J.T., Strom, B.L., 2003. Comparison of logistic regression versus propensity score when the number of events is low and there are multiple confounders. Am. J. Epidemiol. 158, 280-287.

Chaplin, T.M., Aldao, A., 2013. Gender differences in emotion expression in children: a meta-analytic review. Psychol. Bull. 139, 735-765. https://doi.org/10.1037/a0030737

Choné, P., Le Blanc, D., Robert-Bobée, I., 2003. Female labor supply and child care in France. [WWW Document]. URL https://poseidon01.ssrn.com/delivery.php?ID=65911308709002910000109910807007 109503908500703700309010000400511809608903903003300702203403811209909 503009410811701500903308000708600508006407000808802410601002907606809 110100500911003107211810102711500709408702001309509900312300610508600 5083\&EXT=pdf (accessed 7.13.17).

Collombet, C., 2012. Qualité de l'accueil du jeune enfant en France et développement de l'enfant. [WWW Document]. URL https://www.caf.fr/sites/default/files/cnaf/Documents/international/divers/Note\%20qu alit\%C3\%A9\%20de\%201'accueil\%20ambassade\%20RU\%2030\%20nov\%20revue\%2 ODPFAS.pdf (accessed 7.12.17).

Cox, J.L., Holden, J.M., Sagovsky, R., 1987. Detection of postnatal depression. Development of the 10-item Edinburgh Postnatal Depression Scale. Br. J. Psychiatry 150, 782-786. https://doi.org/10.1192/bjp.150.6.782

Crowson, C.S., Schenck, L.A., Green, A.B., Atkinson, E.J., Therneau, T.M., 2013. The Basics of Propensity Scoring and Marginal Structural Models [WWW Document]. URL http://www.mayo.edu/research/documents/biostat-84-pdf/doc-20024406 (accessed 7.12.17).

Cunha, F., Heckman, J.J., 2010. Investing in our young people. Natl. Bur. Econ. Res. NBER Working Paper 16201.

Datta Gupta, N., Simonsen, M., 2010. Non-cognitive child outcomes and universal high quality child care. J. Public Econ. 94, 30-43. https://doi.org/10.1016/j.jpubeco.2009.10.001

David-Alberola, E., 2008. Le métier d'assistante maternelle, DREES No. 636. [WWW Document]. $\quad$ URL http://scuio-univmontp3.centredoc.fr/opac/doc_num.php?explnum_id=802 (accessed 7.12.17).

Doyle, O., Harmon, C.P., Heckman, J.J., Tremblay, R.E., 2009. Investing in early human development: Timing and economic efficiency. Econ. Hum. Biol. 7, 1-6. https://doi.org/10.1016/j.ehb.2009.01.002 
Dustmann, C., Raute, A., Schönberg, U., 2012. Does Universal Child Care Matter? Evidence from a Large Expansion in Pre-School Education. [WWW Document]. URL http://old-hha.asb.dk/nat/helena/workshop0113/Schoenberg.pdf (accessed 9.25.17).

Fagnani, J., 2012. Equal access to quality care: Lessons from France on providing high quality and affordable childcare and early education. [WWW Document]. URL http://sticerd.lse.ac.uk/dps/case/events/France.pdf (accessed 7.12.17).

Fagnani, J., 2006. Family Policy in France. International Encyclopedia of Social Policy, 3, Routledge, pp.501-506 [WWW Document]. URL https://halshs.archivesouvertes.fr/halshs-00101703/document (accessed 7.13.17).

Fuhrer, R., Rouillon, F., 1989. La version française de l'échelle CES-D (Center for Epidemiologic Studies-Depression Scale). Description et traduction de l'échelle d'autoévaluation. [The French version of the CES-D (Center for Epidemiologic Studies-Depression Scale).]. Eur. Psychiatry 4, 163-166.

Geoffroy, M.-C., Côté, S.M., Giguère, C.-É., Dionne, G., Zelazo, P.D., Tremblay, R.E., Boivin, M., Séguin, J.R., 2010. Closing the gap in academic readiness and achievement: the role of early childcare. J. Child Psychol. Psychiatry 51, 1359-1367. https://doi.org/10.1111/j.1469-7610.2010.02316.x

Gialamas, A., Mittinty, M.N., Sawyer, M.G., Zubrick, S.R., Lynch, J., 2015. Time spent in different types of childcare and children's development at school entry: an Australian longitudinal study. Arch. Dis. Child. 100, 226-232. https://doi.org/10.1136/archdischild-2014-306626

Gialamas, A., Sawyer, A.C.P., Mittinty, M.N., Zubrick, S.R., Sawyer, M.G., Lynch, J., 2014. Quality of childcare influences children's attentiveness and emotional regulation at school entry. J. Pediatr. 165, 813-819.e3. https://doi.org/10.1016/j.jpeds.2014.06.011

Goodman, R., 1997. The Strengths and Difficulties Questionnaire: a research note. J. Child Psychol. Psychiatry 38, 581-586.

Haskins, R., 1985. Public School Aggression among Children with Varying Day-Care Experience. Child Dev. 56, 689-703. https://doi.org/10.2307/1129759

Havnes, T., Mogstad, M., 2011. No Child Left Behind: Subsidized Child Care and Children's Long-Run Outcomes. Am. Econ. J. Econ. Policy 3, 97-129.

Heckman, J.J., Stixrud, J., Urzua, S., 2006. The Effects of Cognitive and Noncognitive Abilities on Labor Market Outcomes and Social Behavior. J. Labor Econ. 24, 411-482. https://doi.org/10.1086/504455

Heude, B., Forhan, A., Slama, R., Douhaud, L., Bedel, S., Saurel-Cubizolles, M.-J., Hankard, R., Thiebaugeorges, O., Agostini, M.D., Annesi-Maesano, I., Kaminski, M., Charles, M.-A., Annesi-Maesano, I., Bernard, J.Y., Botton, J., Charles, M.-A., Dargent-Molina, P., Lauzon-Guillain, B. de, Ducimetière, P., Agostini, M. de, Foliguet, B., Forhan, A., Fritel, X., Germa, A., Goua, V., Hankard, R., Heude, B., Kaminski, M., Larroque, B., Lelong, N., Lepeule, J., Magnin, G., Marchand, L., Nabet, C., Pierre, F., Slama, R., Saurel-Cubizolles, M.J., Schweitzer, M., Thiebaugeorges, O., 2016. Cohort Profile: The EDEN mother-child cohort on the prenatal and early postnatal determinants of child health and development. Int. J. Epidemiol. 45, 353-363. https://doi.org/10.1093/ije/dyv151

Jones, B.L., Nagin, D.S., 2007. Advances in Group-Based Trajectory Modeling and an SAS Procedure for Estimating Them. Sociol. Methods Res. 35, 542-571. https://doi.org/10.1177/0049124106292364

Jones, B.L., Nagin, D.S., Roeder, K., 2001. A SAS Procedure Based on Mixture Models for Estimating Developmental Trajectories. Sociol. Methods Res. 29, 374-393. https://doi.org/10.1177/0049124101029003005 
Klasen, H., Crombag, A.-C., 2013. What works where? A systematic review of child and adolescent mental health interventions for low and middle income countries. Soc. Psychiatry Psychiatr. Epidemiol. 48, 595-611. https://doi.org/10.1007/s00127-0120566-X

Lanehart, R.E., Rodriguez de Gil, P., Kim, E.S., Bellara, A.P., Kromrey, J.D., Lee, R.S., 2012. Propensity Score Analysis and Assessment of Propensity Score Approaches Using SAS ${ }^{\circledR} \quad$ Procedures [WWW Document]. URL http://support.sas.com/resources/papers/proceedings12/314-2012.pdf （accessed 7.12.17).

Li, W., Farkas, G., Duncan, G.J., Burchinal, M.R., Vandell, D.L., 2013. Timing of highquality child care and cognitive, language, and preacademic development. Dev. Psychol. 49, 1440-1451. https://doi.org/10.1037/a0030613

Love, J.M., Kisker, E.E., Ross, C., Raikes, H., Constantine, J., Boller, K., Brooks-Gunn, J., Chazan-Cohen, R., Tarullo, L.B., Brady-Smith, C., Fuligni, A.S., Schochet, P.Z., Paulsell, D., Vogel, C., 2005. The effectiveness of early head start for 3-year-old children and their parents: lessons for policy and programs. Dev. Psychol. 41, 885901. https://doi.org/10.1037/0012-1649.41.6.88

Luijk, M.P.C.M., Linting, M., Henrichs, J., Herba, C.M., Verhage, M.L., Schenk, J.J., Arends, L.R., Raat, H., Jaddoe, V.W.V., Hofman, A., Verhulst, F.C., Tiemeier, H., van IJzendoorn, M.H., 2015. Hours in non-parental child care are related to language development in a longitudinal cohort study. Child Care Health Dev. 41, 1188-1198. https://doi.org/10.1111/cch.12238

Lunceford, J.K., Davidian, M., 2004. Stratification and weighting via the propensity score in estimation of causal treatment effects: a comparative study. Stat. Med. 23, 2937-2960. https://doi.org/10.1002/sim.1903

Matthey, S., Henshaw, C., Elliott, S., Barnett, B., 2006. Variability in use of cut-off scores and formats on the Edinburgh Postnatal Depression Scale: implications for clinical and research practice. Arch. Womens Ment. Health 9, 309-315. https://doi.org/10.1007/s00737-006-0152-x

McCartney, K., Burchinal, M., Clarke-Stewart, A., Clarke-Stewart, A., Bub, K.L., Owen, M.T., Belsky, J., NICHD Early Child Care Research Network, 2010. Testing a series of causal propositions relating time in child care to children's externalizing behavior. Dev. Psychol. 46, 1-17. https://doi.org/10.1037/a0017886

Micheau, J., Molière, E., Ohnheiser, S., Chazal, J., 2010. Les modes d'organisations des crèches collectives et les métiers de la petite enfance. DREES, juillet 2010 [WWW Document]. URL http://docplayer.fr/11729032-Les-modes-d-organisations-descreches-collectives-et-les-metiers-de-la-petite-enfance.html (accessed 11.16.16).

Mieloo, C., Raat, H., van Oort, F., Bevaart, F., Vogel, I., Donker, M., Jansen, W., 2012. Validity and reliability of the strengths and difficulties questionnaire in 5-6 year olds: differences by gender or by parental education? PloS One 7, e36805. https://doi.org/10.1371/journal.pone.0036805

Miller, P., Votruba-Drzal, E., 2016. The Role of Family Income Dynamics in Predicting Trajectories of Internalizing and Externalizing Problems. J. Abnorm. Child Psychol. 1-14. https://doi.org/10.1007/s10802-016-0181-5

Mills, M., Präg, P., Tsang, F., Begall, K.H., Derbyshire, J., Kohle, L., Miani, C., Hoorens, S., 2014. Use of childcare in the EU Member States and progress towards the Barcelona targets: short statistical report no. 1. Brussels: RAND Europe/European Commission. [WWW Document]. URL https://pure.uva.nl/ws/files/2182015/165467_429226.pdf (accessed 7.13.17). 
Miner, J.L., Clarke-Stewart, K.A., 2008. Trajectories of externalizing behavior from age 2 to age 9: relations with gender, temperament, ethnicity, parenting, and rater. Dev. Psychol. 44, 771-786. https://doi.org/10.1037/0012-1649.44.3.771

Nagin, D.S., 2005. Group-Based Modeling of Development [WWW Document]. URL http://www.hup.harvard.edu/catalog.php?isbn=9780674016866 (accessed 6.21.16).

Nagin, D.S., Land, K.C., 1993. Age, Criminal Careers, and Population Heterogeneity: Specification and Estimation of a Nonparametric, Mixed Poisson Model*. Criminology 31, 327-362. https://doi.org/10.1111/j.1745-9125.1993.tb01133.x

Nagin, D.S., Odgers, C.L., 2010. Group-Based Trajectory Modeling in Clinical Research. $\begin{array}{llll}\text { Annu. } & \text { Rev. Clin. } & \text { Psychol. }\end{array}$ https://doi.org/10.1146/annurev.clinpsy.121208.131413

Nagin, D.S., Tremblay, R.E., 2005. What Has Been Learned from Group-Based Trajectory Modeling? Examples from Physical Aggression and Other Problem Behaviors. Ann. Am. Acad. Pol. Soc. Sci. 602, 82-117. https://doi.org/10.1177/0002716205280565

OECD, 2016. Public spending on childcare and early education. [WWW Document]. URL https://www.oecd.org/els/family/PF3_1_Public_spending_on_childcare_and_early_ed ucation.pdf (accessed 7.13.17).

Radloff, L.S., 1977. The CES-D Scale A Self-Report Depression Scale for Research in the General Population. Appl. Psychol. Meas. 1, 385-401. https://doi.org/10.1177/014662167700100306

Rijlaarsdam, J., Stevens, G.W.J.M., Ende, J. van der, Hofman, A., Jaddoe, V.W.V., Mackenbach, J.P., Verhulst, F.C., Tiemeier, H., 2013. Economic Disadvantage and Young Children's Emotional and Behavioral Problems: Mechanisms of Risk. J. Abnorm. Child Psychol. 41, 125-137. https://doi.org/10.1007/s10802-012-9655-2

Rosenbaum, P.R., Rubin, D.B., 1983. The central role of the propensity score in observational studies for causal effects. Biometrika 70, 41-55. https://doi.org/10.1093/biomet/70.1.41

Rubenstein, J.L., Howes, C., Boyle, P., 1981. A Two-Year Follow-up of Infants in Community-Based Day Care. J. Child Psychol. Psychiatry 22, 209-218. https://doi.org/10.1111/j.1469-7610.1981.tb00547.x

Shojaei, T., Wazana, A., Pitrou, I., Kovess, V., 2008. The strengths and difficulties questionnaire: validation study in French school-aged children and cross-cultural comparisons. Soc. Psychiatry Psychiatr. Epidemiol. 44, 740-747. https://doi.org/10.1007/s00127-008-0489-8

Shonkoff, J.P., Richmond, J.B., 2009. Investment in early childhood development lays the foundation for a prosperous and sustainable society. [WWW Document]. URL http://www.child-encyclopedia.com/sites/default/files/textes-

experts/en/669/investment-in-early-childhood-development-lays-the-foundation-for-aprosperous-and-sustainable-society.pdf (accessed 7.13.17).

Sterne, J.A.C., White, I.R., Carlin, J.B., Spratt, M., Royston, P., Kenward, M.G., Wood, A.M., Carpenter, J.R., 2009. Multiple imputation for missing data in epidemiological and clinical research: potential and pitfalls. BMJ 338, b2393. https://doi.org/10.1136/bmj.b2393

The NICHD Early Child Care Research, N., 1998. Early Child Care and Self-Control, Compliance, and Problem Behavior at Twenty-Four and Thirty-Six Months. Child Dev. 69, 1145-1170. https://doi.org/10.2307/1132367

Tompson, M.C., Pierre, C.B., Boger, K.D., McKowen, J.W., Chan, P.T., Freed, R.D., 2010. Maternal depression, maternal expressed emotion, and youth psychopathology. J. Abnorm. Child Psychol. 38, 105-117. https://doi.org/10.1007/s10802-009-9349-6 
UNESCO Institute for Statistics, 2016. Official entrance age to primary education (years) | Data [WWW Document]. URL https://data.worldbank.org/indicator/SE.PRM.AGES?end=2016\&start=2016\&view=m ap (accessed 9.25.17).

UNICEF Innocenti Research Centre, 2008. The child care transition, Innocenti Report Card 8. [WWW Document]. URL https://www.unicef-irc.org/publications/pdf/rc8_eng.pdf (accessed 7.13.17).

Vandell, D.L., Belsky, J., Burchinal, M., Steinberg, L., Vandergrift, N., NICHD Early Child Care Research Network, 2010. Do Effects of Early Child Care Extend to Age 15 Years? Results From the NICHD Study of Early Child Care and Youth Development. Child Dev. 81, 737-756. https://doi.org/10.1111/j.1467-8624.2010.01431.x

Villaume, S., 2015. Combien dépensent les familles pour la garde de leurs enfants de moins de 3 ans ? DREES Numéro 930. [WWW Document]. URL http://drees.solidaritessante.gouv.fr/IMG/pdf/er930.pdf (accessed 7.12.17).

Wachs, T.D., Georgieff, M., Cusick, S., McEwen, B., 2014. Issues in the timing of integrated early interventions: contributions from nutrition, neuroscience and psychological research. Ann. N. Y. Acad. Sci. 1308, 89-106. https://doi.org/10.1111/nyas.12314

Walker, S.P., Chang, S.M., Vera-Hernández, M., Grantham-McGregor, S., 2011. Early childhood stimulation benefits adult competence and reduces violent behavior. Pediatrics 127, 849-857. https://doi.org/10.1542/peds.2010-2231

$\mathrm{Xu}$, S., Ross, C., Raebel, M.A., Shetterly, S., Blanchette, C., Smith, D., 2010. Use of stabilized inverse propensity scores as weights to directly estimate relative risk and its confidence intervals. Value Health J. Int. Soc. Pharmacoeconomics Outcomes Res. 13, 273-277. https://doi.org/10.1111/j.1524-4733.2009.00671.x

Yamauchi, C., Leigh, A., 2011. Which children benefit from non-parental care? Econ. Educ. Rev., Special Issue: Economic Returns to Education 30, 1468-1490. https://doi.org/10.1016/j.econedurev.2011.07.012

Youthinmind, 2015. Information for researchers and professionals about the Strengths \& Difficulties Questionnaires. [WWW Document]. URL http://www.youthinmind.com/ (accessed 6.8.16).

Yuan, Y.C., n.d. Multiple Imputation for Missing Data: Concepts and New Development. [WWW Document]. URL https://stats.idre.ucla.edu/wpcontent/uploads/2016/02/multipleimputation.pdf (accessed 7.13.17).

Zachrisson, H.D., Dearing, E., Lekhal, R., Toppelberg, C.O., 2013. Little evidence that time in child care causes externalizing problems during early childhood in Norway. Child Dev. 84, 1152-1170. https://doi.org/10.1111/cdev.12040 
Table 1: Characteristics of children participating in the EDEN mother-child cohort in relation to childcare between 0-3 years $(n=1428,2003-2011$, France). $\%(\mathrm{~N})$ or mean (standard deviation), p-value.

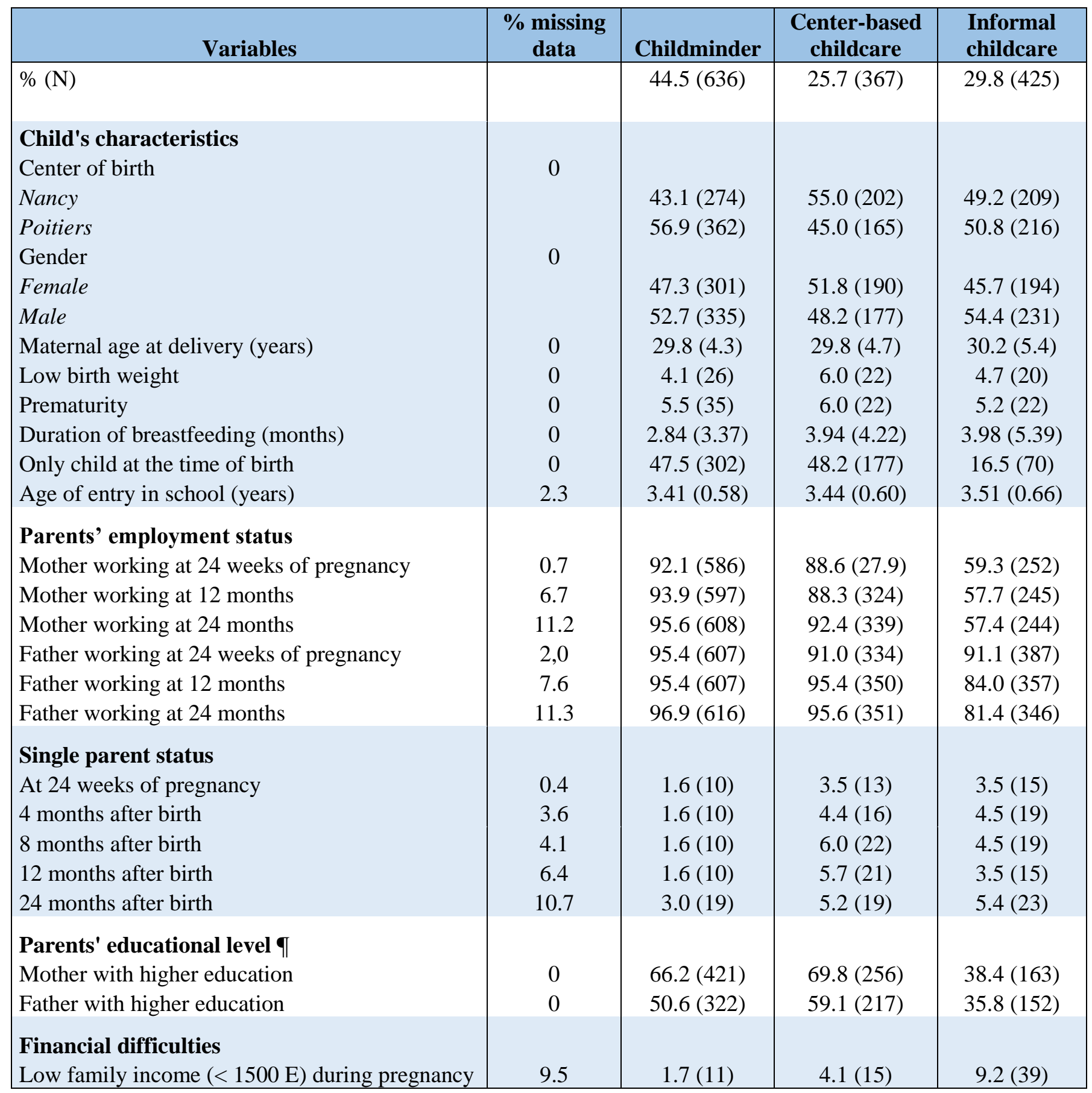




\begin{tabular}{|l|c|c|c|c|}
\hline >= financial difficulty during pregnancy & 0.4 & $47.3(301)$ & $49.6(182)$ & $56.7(241)$ \\
Low family income during 1st year & 9.3 & $4.9(31)$ & $9.3(34)$ & $31.8(135)$ \\
>= financial difficulty felt in 1st year & 7.1 & $23.9(152)$ & $25.9(95)$ & $43.3(184)$ \\
Low family income during 2nd year & 9.5 & $3.9(25)$ & $8.2(30)$ & $32.0(136)$ \\
>= financial difficulty during 2nd year & 10.4 & $50.0(318)$ & $55.0(202)$ & $63.1(268)$ \\
\hline
\end{tabular}

Table 1 (part 2)

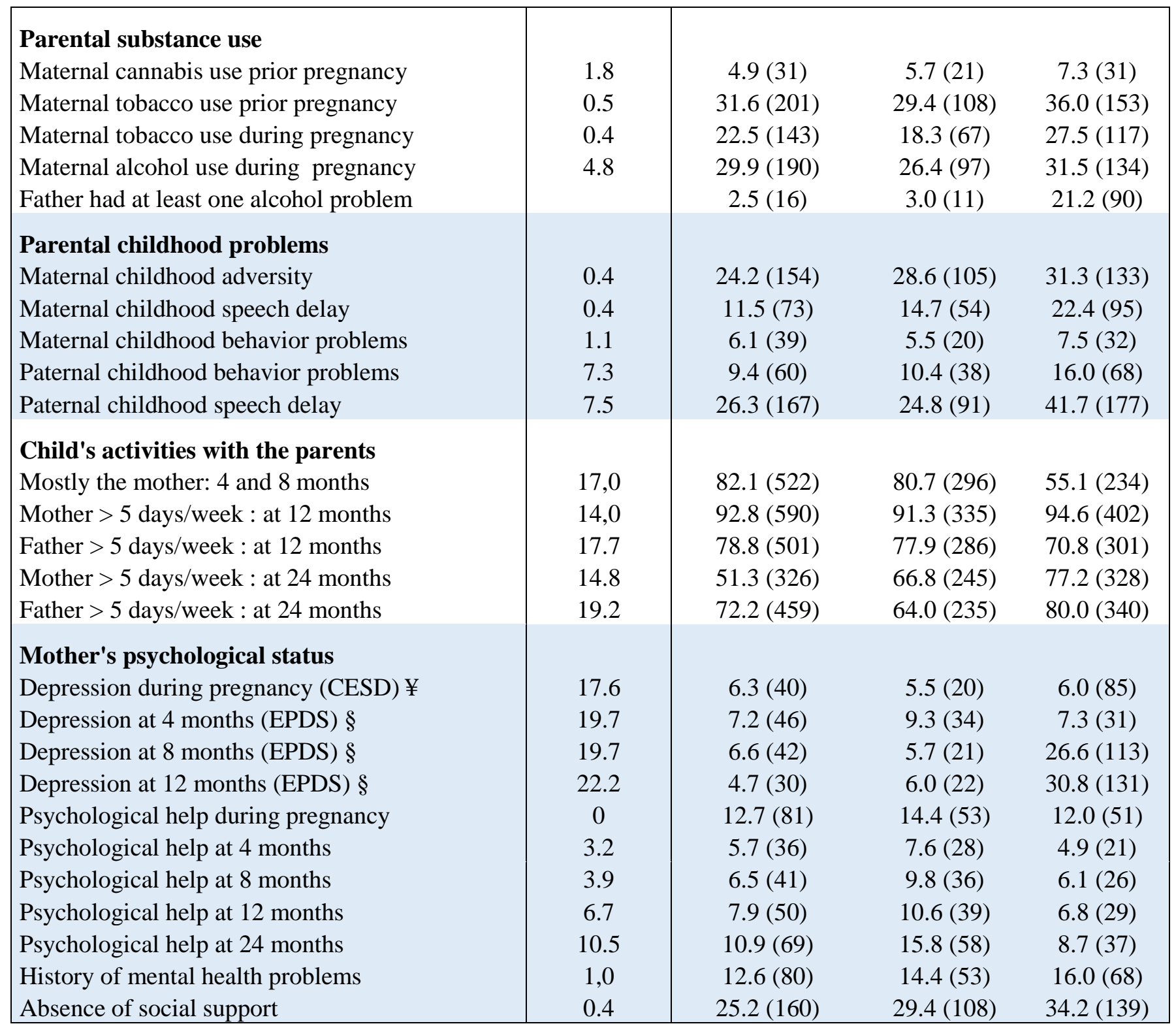

\footnotetext{
$\%(\mathrm{~N})$ or Mean (SD) for continuous variables

II BAC or Baccalauréat in France is equivalent to Higher School Certificate, or Matura in other European countries

$¥$ CES-D: Center of Epidemiological Studies Depression scale

$\S$ EPDS: Edinburg Postnatal Depression Scale
} 
Table 2: Comparison of SDQ total scores at 3, 5.5 and 8 years among children from childminder, center-based childcare and informal childcare, with successively children in informal care and children in center-based childcare as reference (at least 1 year in center-based childcare for comparison of time in childcare).

\begin{tabular}{|c|c|c|c|c|}
\hline Age & Childcare type & Child-minder & $\begin{array}{c}\text { Center-based } \\
\text { childcare }\end{array}$ & $\begin{array}{l}\text { Informal } \\
\text { childcare }\end{array}$ \\
\hline 3 years & $\begin{array}{l}\text { N } \\
\text { Mean SDQ score (SD) } \\
p \text { (compared to IC) } \\
p \text { (compared to } C B C)\end{array}$ & $\begin{array}{c}593 \\
9.98(4.56) \\
0.0111 \\
0.0013\end{array}$ & $\begin{array}{c}337 \\
8.94(4.72) \\
<0.0001 \\
-\end{array}$ & $\begin{array}{c}374 \\
10.77(4.94) \\
- \\
<0.0001\end{array}$ \\
\hline 5.5 years & $\begin{array}{l}\text { N } \\
\text { Mean SDQ score (SD) } \\
\text { p (compared to IC) } \\
\text { p (compared to } C B C)\end{array}$ & $\begin{array}{c}537 \\
8.97(5.42) \\
0.8340 \\
0.0013\end{array}$ & $\begin{array}{c}300 \\
7.76(4.97) \\
0.0038 \\
-\end{array}$ & $\begin{array}{c}346 \\
9.28(4.99) \\
- \\
0.0002\end{array}$ \\
\hline 8 years & $\begin{array}{l}\text { N } \\
\text { Mean SDQ score (SD) } \\
p \text { (compared to } I C) \\
\text { p (compared to } C B C)\end{array}$ & $\begin{array}{c}401 \\
8.95(5.24) \\
0.3799 \\
0.0024\end{array}$ & $\begin{array}{c}235 \\
7.66(5.08) \\
0.0002 \\
-\end{array}$ & $\begin{array}{c}238 \\
9.03(5.08) \\
- \\
0.0038\end{array}$ \\
\hline
\end{tabular}

\begin{tabular}{|c|c|c|c|c|c|c|}
\hline Age & Time in childcare & $\begin{array}{c}C M<1 \\
Y R\end{array}$ & $\begin{array}{c}C M>=1 \\
Y R\end{array}$ & $\begin{array}{c}C B C<1 \\
Y R\end{array}$ & $\begin{array}{c}C B C>=1 \\
Y R\end{array}$ & IC \\
\hline 3 years & $\begin{array}{l}\text { N } \\
\text { Mean SDQ score (SD) } \\
p \text { (compared to IC) } \\
p \text { (compared to } C B C)\end{array}$ & $\begin{array}{c}151 \\
10.50(4.61) \\
0.5432 \\
0.0003\end{array}$ & $\begin{array}{c}442 \\
9.81(4.53) \\
0.0035 \\
0.0040\end{array}$ & $\begin{array}{c}154 \\
9.34(4.95) \\
0.0015 \\
0.1589\end{array}$ & $\begin{array}{c}183 \\
8.61(4.51) \\
<0.0001 \\
-\end{array}$ & $\begin{array}{c}374 \\
10.77(4.94) \\
- \\
<0.0001\end{array}$ \\
\hline 5.5 years & $\begin{array}{l}\text { N } \\
\text { Mean SDQ score (SD) } \\
p(\text { compared to IC) } \\
p \text { (compared to } C B C)\end{array}$ & $\begin{array}{c}141 \\
9.82(5.39) \\
0.2999 \\
<0.0001\end{array}$ & $\begin{array}{c}396 \\
8.66(5.40) \\
0.1053 \\
0.0018\end{array}$ & $\begin{array}{c}129 \\
8.53(5.52) \\
0.1578 \\
0.0263\end{array}$ & $\begin{array}{c}171 \\
7.19(4.45) \\
<0.0001 \\
-\end{array}$ & $\begin{array}{c}346 \\
9.28(4.99) \\
- \\
<0.0001\end{array}$ \\
\hline 8 years & $\begin{array}{l}\mathrm{N} \\
\text { Mean SDQ score (SD) } \\
p \text { (compared to } I C) \\
p \text { (compared to } C B C)\end{array}$ & $\begin{array}{c}80 \\
10.24(4.82) \\
0.0705 \\
0.0002\end{array}$ & $\begin{array}{c}321 \\
8.62(5.30) \\
0.351 \\
0.0310\end{array}$ & $\begin{array}{c}98 \\
7.89(5.44) \\
0.0638 \\
0.5581\end{array}$ & $\begin{array}{c}137 \\
7.49(4.82) \\
0.0052 \\
-\end{array}$ & $\begin{array}{c}238 \\
9.03(5.08) \\
\cdot \\
0.0052\end{array}$ \\
\hline
\end{tabular}

$\boldsymbol{C M}=$ childminder $; \boldsymbol{C B C}=$ center-based childcare $; \boldsymbol{I C}=$ informal childcare

$\mathbf{C M}<1$ YR: child-minder for less than 1 year; $\mathbf{C M}>=\mathbf{1} \mathbf{Y R}$ : child-minder for at least 1 year; $\mathbf{C B C}<\mathbf{1}$ YR: center-based childcare for less than 1 year; $\mathbf{C B C ~ > = 1 ~ Y R : ~ c e n t e r - b a s e d ~}$ childcare for at least 1 year; IC: informal childcare. 
Table 3a: Association between childcare type (age 0-3 years) and children's behavioral trajectories (age 3-8 years) in the French EDEN study. Bivariate analysis with multinomial logistic regression (Informal care, IC, as reference childcare OR in the left column and centerbased childcare, CBC, as reference in the right) - 95\% Confidence Interval.

\begin{tabular}{|c|c|c|c|c|c|c|c|}
\hline \multicolumn{2}{|l|}{ Unadjusted } & \multicolumn{3}{|c|}{$\underline{\text { IC as reference }}$} & \multicolumn{3}{|c|}{$\underline{C B C \text { as reference }}$} \\
\hline Childcare type & Trajectories & OR & $95 \% \mathrm{CI}$ & $p$ & OR & $95 \% \mathrm{CI}$ & $p$ \\
\hline \multirow[t]{2}{*}{ CM } & Intermediate & 0.81 & $0.62-1.04$ & 0.1011 & 1.58 & $1.20-2.08$ & 0.0012 \\
\hline & High & 0.85 & $0.56-1.30$ & 0.4528 & 1.92 & $1.17-3.16$ & 0.0105 \\
\hline \multirow[t]{2}{*}{$C B C$} & Intermediate & 0.51 & $0.38-0.69$ & $<0.0001$ & - & - & - \\
\hline & High & 0.44 & $0.26-0.76$ & 0.0027 & - & - & - \\
\hline \multirow[t]{2}{*}{$I C$} & Intermediate & - & - & - & 1.96 & $1.46-2.65$ & $<0.0001$ \\
\hline & High & - & - & - & 2.26 & $1.33-3.84$ & 0.0027 \\
\hline
\end{tabular}

$\boldsymbol{C M}=$ childminder $; \boldsymbol{C B C}=$ center -based childcare $; \boldsymbol{I}=$ informal childcare

Table 3b: Association between time spent in childcare (age 0-3 years) and children's behavioral trajectories (age 3-8 years) - low trajectory as reference- in the French EDEN study. Bivariate analysis using multinomial logistic regression (informal childcare as reference group in the left column and center-based childcare for at least 1 year as reference in the left column). OR- 95\% Confidence Interval.

\begin{tabular}{|c|c|c|c|c|c|c|c|}
\hline \multicolumn{2}{|l|}{ Unadjusted } & \multicolumn{3}{|c|}{ IC as reference } & \multicolumn{3}{|c|}{$\underline{C B C>=1 Y R \text { as reference }}$} \\
\hline Time in childcare & Trajectories & OR & $95 \% \mathrm{CI}$ & $p$ & OR & $95 \% \mathrm{CI}$ & $p$ \\
\hline \multirow[t]{2}{*}{$C M<1 Y R(n=174)$} & Intermediate & 1.14 & $0.78-1.66$ & 0.5053 & 2.45 & $1.58-3.80$ & $<0.0001$ \\
\hline & High & 1.24 & $0.69-2.23$ & 0.4772 & 3.84 & $1.71-8.61$ & 0.0011 \\
\hline \multirow[t]{2}{*}{$C M>=1 Y R(n=462)$} & Intermediate & 0.71 & $0.54-0.94$ & 0.0167 & 1.53 & $1.06-2.19$ & 0.0216 \\
\hline & High & 0.75 & $0.47-1.19$ & 0.2277 & 2.28 & $1.11-4.70$ & 0.0247 \\
\hline \multirow[t]{2}{*}{$C B C<1 Y R(n=167)$} & Intermediate & 0.57 & $0.39-0.84$ & 0.0043 & 1.23 & $0.78-1.92$ & 0.3715 \\
\hline & High & 0.61 & $0.32-1.17$ & 0.1376 & 1.87 & $0.80-4.38$ & 0.1518 \\
\hline \multirow[t]{2}{*}{$C B C>=1 Y R(n=200)$} & Intermediate & 0.46 & $0.32-0.67$ & $<0.0001$ & - & - & - \\
\hline & High & 0.32 & $0.16-0.66$ & 0.0022 & - & - & - \\
\hline \multirow[t]{2}{*}{$I C(n=425)$} & Intermediate & - & - & - & 2.15 & $1.50-3.10$ & $<0.0001$ \\
\hline & High & - & - & - & 3.10 & $1.51-6.37$ & 0.0021 \\
\hline
\end{tabular}

$\mathbf{C M}<1$ YR: childminder for less than 1 year; $\mathbf{C M}>=\mathbf{1}$ YR: childminder for at least 1 year; $\mathbf{C B}<\mathbf{1} \mathbf{Y R}$ : center-based childcare for less than 1 year; $\mathbf{C B}>=\mathbf{1}$ YR: center-based childcare for at least 1 year; IC: informal childcare. 
Table 4a: Association between childcare type (age 0-3 years) and children's behavioral trajectories- low trajectory as reference- (age 3-8 years) in the French EDEN study. IPWsadjusted multinomial logistic regression ${ }^{2}$ (informal childcare- IC- as reference group in the left table and center-based childcare- $\mathrm{CBC}$ - as reference in the right column). OR- 95\% Confidence Interval.

\begin{tabular}{|c|l|ccc|ccc|}
\hline \multicolumn{2}{|c|}{ Adjusted } & \multicolumn{3}{c|}{ IC as reference } & \multicolumn{3}{c|}{ CBC as reference } \\
\hline Childcare type & Trajectories & OR & $\mathbf{9 5 \%}$ CI & $p$ & OR & $\mathbf{9 5 \%}$ CI & $p$ \\
CM $(\boldsymbol{n = 6 3 6})$ & Intermediate & $\mathbf{0 . 8 4}$ & $0.59-1.19$ & $\mathbf{0 . 3 2 0 4}$ & $\mathbf{1 . 2 1}$ & $0.87-1.70$ & $\mathbf{0 . 2 5 6 8}$ \\
& High & $\mathbf{1 . 5 2}$ & $0.89-2.61$ & $\mathbf{0 . 1 2 6 8}$ & $\mathbf{1 . 4 4}$ & $0.46-4.54$ & $\mathbf{0 . 5 0 1 1}$ \\
CBC $(\boldsymbol{n = 3 6 7 )})$ & Intermediate & $\mathbf{0 . 6 9}$ & $0.46-1.04$ & $\mathbf{0 . 0 7 5 6}$ & - & - & - \\
& High & $\mathbf{1 . 0 5}$ & $0.31-3.54$ & $\mathbf{0 . 9 2 9 4}$ & - & - & - \\
IC $(\boldsymbol{n = 4 2 5 )}$ & Intermediate & - & - & - & $\mathbf{1 . 4 5}$ & $0.96-2.18$ & $\mathbf{0 . 0 7 5 6}$ \\
& High & - & - & - & $\mathbf{0 . 9 5}$ & $0.28-3.20$ & $\mathbf{0 . 9 2 9 4}$ \\
\hline
\end{tabular}

$\boldsymbol{C M}=$ child-minder $; \boldsymbol{C B C}=$ center-based childcare $; \boldsymbol{I}=$ informal childcare

Table 4b: Association between time spent in childcare (age 0-3 years) and children's behavioral trajectories (age 3-8 years) - low trajectory as reference - in the French EDEN study. IPW-adjusted multinomial logistic regression ${ }^{3}$ (using informal childcare as reference group in the left column and center-based childcare for at least one year in the right column). OR- 95\% Confidence Interval.

\begin{tabular}{|c|c|c|c|c|c|c|c|}
\hline \multicolumn{2}{|l|}{ Adjusted } & \multicolumn{3}{|c|}{$\underline{I C \text { as reference }}$} & \multicolumn{3}{|c|}{$\underline{C B C>=1 Y R \text { as reference }}$} \\
\hline Time in childcare & Trajectories & OR & $95 \% \mathrm{CI}$ & $p$ & OR & $95 \% \mathrm{CI}$ & $p$ \\
\hline \multirow[t]{2}{*}{$C M<1 Y R(n=174)$} & Intermediate & 1.04 & $0.71-1.53$ & 0.8394 & 1.55 & $1.04-2.33$ & 0.0328 \\
\hline & High & 2.53 & $1.26-5.07$ & 0.0098 & 5.96 & $2.93-12.15$ & $<0.0001$ \\
\hline \multirow[t]{2}{*}{$C M>=1 Y R(n=462)$} & Intermediate & 0.77 & $0.52-1.13$ & 0.1871 & 1.15 & $0.76-1.73$ & 0.4987 \\
\hline & High & 1.20 & $0.62-2.32$ & 0.5817 & 2.83 & $1.38-5.82$ & 0.0046 \\
\hline \multirow[t]{2}{*}{$C B C<1 Y R(n=167)$} & Intermediate & 0.70 & $0.48-1.04$ & 0.0809 & 1.05 & $0.67-1.65$ & 0.8223 \\
\hline & High & 1.06 & $0.47-2.36$ & 0.8911 & 2.49 & $1.07-2.16$ & 0.0337 \\
\hline \multirow{2}{*}{$\begin{array}{r}C B C>=1 Y R \\
(n=200)\end{array}$} & Intermediate & 0.67 & $0.46-0.97$ & 0.0330 & - & - & - \\
\hline & High & 0.42 & $0.19-0.93$ & 0.0331 & - & - & - \\
\hline \multirow[t]{2}{*}{$I C(n=425)$} & Intermediate & - & - & - & 1.49 & $1.03-2.16$ & 0.0330 \\
\hline & High & - & - & - & 2.36 & $1.07-5.19$ & 0.0331 \\
\hline
\end{tabular}

$\mathbf{C M}<1$ YR: child-minder for less than 1 year; $\mathbf{C M}>=\mathbf{1}$ YR: child-minder for at least 1 year; $\mathbf{C B}<\mathbf{1} \mathbf{Y R}$ : center-based childcare for less than 1 year; $\mathbf{C B}>=\mathbf{1}$ YR: center-based childcare for at least 1 year; IC: informal childcare.

\footnotetext{
${ }^{2,2}$ Control variables include among others: center of study, children's characteristics (sex, prematurity, breastfeeding), parents' education level, financial status, mothers' psychological status, children's activities with parents, parental childhood problems, and mothers' substance abuse.
} 
Table 5: Childcare type/time spent in childcare and children's emotional and behavioral symptoms in the French EDEN study: stratified analyses ${ }^{4}$ by sex $^{5}$; mother's number of years of education; mother's depression status and family's financial difficulties status. Successive comparison to informal care (IC) and center-based care (CBC); OR of having a trajectory of high symptom levels - 95\% CI.

\begin{tabular}{|c|c|c|c|c|c|c|c|c|c|c|c|c|}
\hline \multirow{2}{*}{$\begin{array}{c}\text { CHILDCARE } \\
\text { TYPE }\end{array}$} & \multicolumn{3}{|c|}{ IC as reference } & \multicolumn{3}{|c|}{ CBC as reference } & \multicolumn{3}{|c|}{ IC as reference } & \multicolumn{3}{|c|}{ CBC as reference } \\
\hline & OR & $95 \% \mathrm{CI}$ & $p$ & OR & $95 \% \mathrm{CI}$ & $p$ & OR & $95 \% \mathrm{CI}$ & $p$ & OR & $95 \% \mathrm{CI}$ & $p$ \\
\hline & \multicolumn{6}{|c|}{ GIRLS (N = 685) } & \multicolumn{6}{|c|}{ BOYS $(N=743)$} \\
\hline $\mathbf{C M}$ & 0.54 & $0.35-0.82$ & 0.0039 & 1.01 & $0.49-2.08$ & 0.9718 & 1.59 & $1.03-2.46$ & 0.0351 & 1.54 & $0.98-2.42$ & 0.0583 \\
\hline $\mathrm{CBC}$ & 0.53 & $0.26-1.09$ & 0.0828 & - & & - & 1.03 & $0.60-1.70$ & 0.9019 & - & & - \\
\hline \multirow[t]{2}{*}{ IC } & - & - & - & 1.89 & $0.91-3.92$ & 0.0828 & - & - & - & 0.97 & $0.56-1.66$ & 0.9019 \\
\hline & \multicolumn{6}{|c|}{$<$ BAC +2 YEARS $(\mathrm{N}=588)$} & \multicolumn{6}{|c|}{$>=$ BAC +2 YEARS $(N=840)$} \\
\hline $\mathbf{C M}$ & 1.08 & $0.67-1.75$ & 0.7505 & 1.38 & $0.56-3.40$ & 0.4643 & 0.93 & $0.63-1.37$ & 0.7057 & 1.21 & $0.83-1.76$ & 0.3156 \\
\hline $\mathrm{CBC}$ & 0.78 & $0.29-2.15$ & 0.6134 & - & - & - & 0.77 & $0.52-1.13$ & 0.1744 & - & - & - \\
\hline \multirow[t]{2}{*}{ IC } & - & - & - & 1.28 & $0.47-3.50$ & 0.6134 & - & - & - & 1.31 & $0.89-1.92$ & 0.1744 \\
\hline & \multicolumn{6}{|c|}{ NO DEPRESSION ( $N=1085)$} & \multicolumn{6}{|c|}{ DEPRESSION $(\mathrm{N}=\mathbf{3 4 3})$} \\
\hline $\mathbf{C M}$ & 0.89 & $0.64-1.24$ & 0.5001 & 1.21 & $0.88-1.67$ & 0.2353 & 1.1 & $0.47-2.60$ & 0.8251 & 1.48 & $0.72-3.02$ & 0.2851 \\
\hline CBC & 0.74 & $0.52-1.04$ & 0.0787 & - & - & - & 0.74 & $0.31-1.80$ & 0.5028 & - & - & - \\
\hline \multirow[t]{2}{*}{ IC } & & & & 1.36 & $0.96-1.92$ & 0.0787 & - & - & - & 1.34 & $0.55-3.25$ & 0.5028 \\
\hline & \multicolumn{6}{|c|}{ NO FINANCIAL DIFFICULTIES ( $\mathrm{N}=1159$ ) } & \multicolumn{6}{|c|}{ FINANCIAL DIFFICULTIES ( $\mathrm{N}=269$ ) } \\
\hline $\mathbf{C M}$ & 1.09 & $0.78-1.51$ & 0.6134 & 1.65 & $1.16-2.36$ & 0.0059 & 1.03 & $0.29-3.65$ & 0.9585 & 0.52 & $0.18-1.47$ & 0.2162 \\
\hline CBC & 0.66 & $0.44-0.98$ & 0.0408 & - & - & - & 1.99 & $0.40-9.97$ & 0.3759 & - & - & - \\
\hline IC & - & - & - & 1.52 & $1.02-2.27$ & 0.0408 & - & - & - & 0.5 & $0.10-2.52$ & 0.3759 \\
\hline
\end{tabular}

\begin{tabular}{|c|c|c|c|c|c|c|c|c|c|c|c|c|}
\hline \multirow{3}{*}{$\mathrm{CM}<1 \mathrm{YR}$} & \multicolumn{3}{|c|}{ IC as reference } & \multicolumn{3}{|c|}{$C B C>=1$ year as reference } & \multicolumn{3}{|c|}{ IC as reference } & \multicolumn{3}{|c|}{$\begin{array}{c}C B C>=1 \text { year as } \\
\text { reference }\end{array}$} \\
\hline & \multicolumn{6}{|c|}{ GIRLS } & \multicolumn{6}{|c|}{ BOYS } \\
\hline & 0.63 & $0.38-1.06$ & 0.0847 & 1.86 & $1.08-3.18$ & 0.0244 & 2.36 & $1.42-3.90$ & 0.0009 & 2.33 & $1.34-4.06$ & 0.0029 \\
\hline $\mathrm{CM}>=1 \mathrm{YR}$ & 0.42 & $0.25-0.72$ & 0.0014 & 1.24 & $0.71-2.15$ & 0.4468 & 1.44 & $0.89-2.35$ & 0.1403 & 1.43 & $0.83-2.45$ & 0.1953 \\
\hline $\mathrm{CBC}<1 \mathrm{YR}$ & 0.53 & $0.32-0.87$ & 0.0128 & 1.55 & $0.88-2.73$ & 0.1301 & 1.01 & $0.58-1.76$ & 0.9645 & 00 & $0.54-1.87$ & 0.9933 \\
\hline $\mathrm{CBC}>=1 \mathrm{YR}$ & 0.34 & $0.20-0.59$ & 0.0001 & & - & - & 1.01 & $0.63-1.62$ & 0.9676 & - & - & - \\
\hline \multirow[t]{2}{*}{ IC } & - & - & - & 2.93 & $1.71-5.04$ & 0.0001 & - & - & - & 0.99 & $0.62-1.59$ & 0.9676 \\
\hline & \multicolumn{6}{|c|}{$<$ BAC +2 YEARS } & \multicolumn{6}{|c|}{$>=$ BAC +2 YEARS } \\
\hline $\mathrm{CM}<1 \mathrm{YR}$ & 1.73 & $0.95-3.18$ & 0.0750 & 2.34 & $1.22-4.48$ & 0.0109 & 1.04 & $0.65-1.66$ & 0.8693 & 1.81 & $1.10-2.98$ & 0.0205 \\
\hline $\mathrm{CM}>=1 \mathrm{YR}$ & 0.89 & $0.50-1.58$ & 0.6834 & 1.19 & $0.66-2.18$ & 0.5619 & 0.81 & $0.51-1.29$ & 0.3760 & 1.41 & $0.85-2.33$ & 0.1803 \\
\hline $\mathrm{CBC}<1 \mathrm{YR}$ & 0.59 & $0.30-1.16$ & 0.1232 & 0.79 & $0.41-1.55$ & 0.4939 & 0.94 & $0.59-1.48$ & 0.7745 & 1.62 & $0.95-2.76$ & 0.0732 \\
\hline $\mathrm{CBC}>=1 \mathrm{YR}$ & 0.74 & $0.42-1.33$ & 0.3143 & - & - & - & 0.58 & $0.36-0.93$ & 0.0252 & - & - & - \\
\hline \multirow[t]{2}{*}{ IC } & - & - & - & 1.35 & $0.75-2.41$ & 0.3143 & - & - & - & 1.74 & $1.07-2.81$ & 0.0252 \\
\hline & \multicolumn{6}{|c|}{ NO DEPRESSION } & \multicolumn{6}{|c|}{ DEPRESSION } \\
\hline $\mathrm{CM}<1 \mathrm{YR}$ & 1.12 & $0.74-1.68$ & 0.5933 & 2-00 & $1.28-3.14$ & 0.0025 & 1.45 & $0.52-4.08$ & 0.4720 & 1.33 & $0.52-3.41$ & 0.5579 \\
\hline$C M>=1 Y R$ & 0.81 & $0.53-1.24$ & 0.3320 & 1.45 & $0.94-2.24$ & 0.0918 & 0.78 & $0.28-2.15$ & 0.6269 & 0.71 & $0.29-1.74$ & 0.4576 \\
\hline $\mathrm{CBC}<1 \mathrm{YR}$ & 0.77 & $0.52-1.13$ & 0.1821 & 1.37 & $0.84-2.26$ & 0.2060 & 0.47 & $0.16-1.37$ & 0.1614 & 0.43 & $0.17-1.09$ & 0.0760 \\
\hline
\end{tabular}

\footnotetext{
${ }^{4}$ Control variables include among others: center of study, children's characteristics (sex, prematurity, breastfeeding), parents' education level, financial status, mothers' psychological status, children's activities with parents, parental childhood problems, and mothers' substance abuse.

${ }^{5}$ For each stratified analysis a model was constructed excluding the variable of stratification. For example, for analyses stratified by sex, one model was constructed for boys and one for girls, both containing the same control variables but did not contain the variable for sex.
} 


\begin{tabular}{|c|c|c|c|c|c|c|c|c|c|c|c|c|}
\hline $\begin{array}{c}\text { CBC > }=1 \text { YR } \\
\text { IC }\end{array}$ & $\begin{array}{c}0.56 \\
- \\
\end{array}$ & $\begin{array}{c}0.34-0.91 \\
-\end{array}$ & $\begin{array}{c}0.0214 \\
- \\
\end{array}$ & $\begin{array}{c}- \\
1.79\end{array}$ & $\begin{array}{c}- \\
1.09-2.94\end{array}$ & $\begin{array}{c}- \\
0.0214\end{array}$ & $\begin{array}{c}1.10 \\
-\end{array}$ & $\begin{array}{c}0.37-3.25 \\
- \\
\end{array}$ & $\begin{array}{c}0.8667 \\
- \\
\end{array}$ & $\begin{array}{c}- \\
0.91 \\
\end{array}$ & $\begin{array}{c}- \\
0.31-2.71\end{array}$ & $\begin{array}{c}- \\
0.8667 \\
\end{array}$ \\
\hline & \multicolumn{6}{|c|}{ NO FINANCIAL DIFFICULTIES } & \multicolumn{6}{|c|}{ FINANCIAL DIFFICULTIES } \\
\hline $\mathrm{CM}<1 \mathrm{YR}$ & 1.42 & $0.94-2.16$ & 0.0941 & 2.52 & $1.68-3.77$ & $<0.0001$ & 0.89 & $0.25-3.15$ & 0.8490 & 0.48 & $0.11-2.02$ & 0.3114 \\
\hline $\mathrm{CM}>=\mathbf{1} \mathrm{YR}$ & 0.86 & $0.58-1.27$ & 0.4474 & 1.52 & $1.02-2.26$ & 0.0393 & 1.20 & $0.32-4.45$ & 0.7808 & 0.64 & $0.16-2.66$ & 0.5410 \\
\hline $\mathrm{CBC}<1 \mathrm{YR}$ & 0.67 & $0.44-1.03$ & 0.0665 & 1.18 & $0.76-1.85$ & 0.4580 & 1.38 & $0.35-5.43$ & 0.6348 & 0.74 & $0.17-1.67$ & 0.6785 \\
\hline $\mathrm{CBC}>=1 \mathrm{YR}$ & 0.57 & $0.38-0.84$ & 0.0051 & - & - & - & 1.86 & $0.60-5.81$ & 0.2825 & - & - & - \\
\hline IC & - & - & - & 1.77 & $1.19-2.63$ & 0.0051 & - & - & - & 0.54 & $0.17-1.67$ & 0.2825 \\
\hline
\end{tabular}

$\boldsymbol{C M}=$ childminder $; \boldsymbol{C B C}=$ center -based childcare $\boldsymbol{I} \boldsymbol{C}=$ informal childcare

$\mathbf{C M}<1$ YR: child-minder for less than 1 year; $\mathbf{C M}>=\mathbf{1} \mathbf{Y R}$ : child-minder for at least 1 year; $\mathbf{C B C}$ $<1$ YR: center-based childcare for less than 1 year; $\mathbf{C B C}>=1$ YR: center-based childcare for at least 1 year; IC: informal childcare. 
Supplementary Figure 1: Distribution of propensity scores associated with belonging to each of three childcare groups $(1=$ child-minder; $2=$ center-based care; $3=$ informal care $)$ in the French EDEN study.

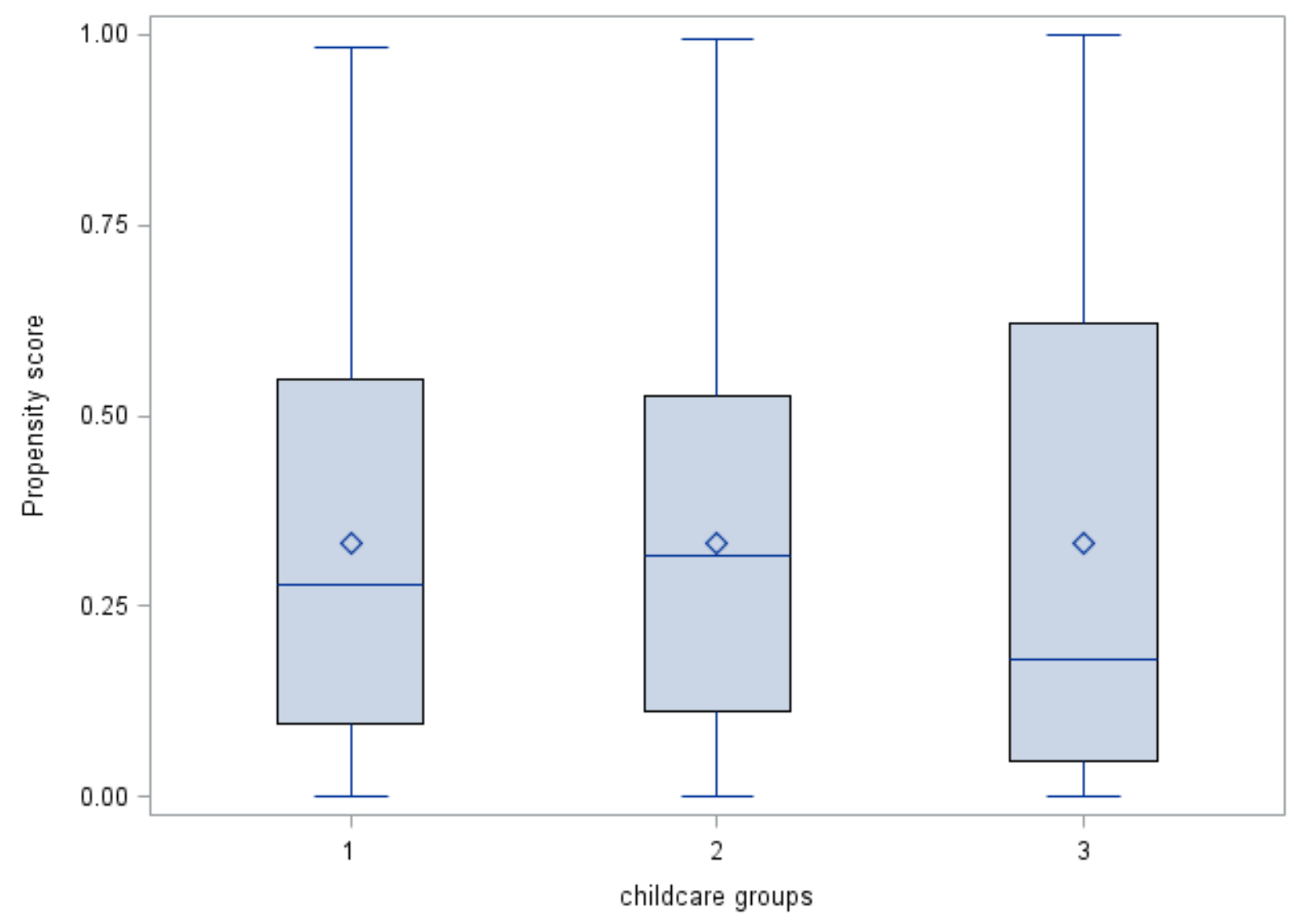


Supplementary Table 1: Childcare type and other covariates (ages 0 to 3 years) and children's behavioral trajectories (ages 3.5-8 years) in the French EDEN mother-child cohort. Bivariate multinomial logistic regression analyses (informal care serving as the reference group). OR- 95\% Confidence Interval.

\begin{tabular}{|c|c|c|c|c|c|c|c|c|}
\hline \multirow[t]{2}{*}{ Variables } & \multirow{2}{*}{\multicolumn{2}{|c|}{$\begin{array}{l}\text { Low }(n=721) \\
\text { OR }\end{array}$}} & \multicolumn{3}{|c|}{ Intermediate $(n=574)$} & \multicolumn{3}{|c|}{ High $(n=133)$} \\
\hline & & & OR & $95 \%$ IC & $p$ & OR & $95 \%$ IC & $p$ \\
\hline \multicolumn{9}{|l|}{ Type of childcare } \\
\hline Informal care & 1.00 & ref & 1.00 & ref & & 1.00 & ref & \\
\hline Child-minder & 1.00 & ref & 0.81 & $0.62-1.04$ & 0.1011 & 0.85 & $0.56-1.30$ & 0.4528 \\
\hline Center-based care & 1.00 & ref & 0.51 & $0.38-0.69$ & $<0.0001$ & 0.44 & $0.26-0.76$ & 0.0027 \\
\hline \multicolumn{9}{|l|}{ Child's characteristics } \\
\hline Center of birth: Poitiers with Nancy as reference & 1.00 & ref & 1.24 & $1.00-1.55$ & 0.0551 & 1.17 & $0.81-1.69$ & 0.4125 \\
\hline Gender: Male & 1.00 & ref & 1.22 & $0.98-1.52$ & 0.0735 & 2.34 & $1.58-3.46$ & $<0.0001$ \\
\hline Maternal age at delivery (years) & 1.00 & ref & 1.36 & $1.13-1.65$ & 0.0015 & 1.74 & $1.26-2.40$ & 0.0008 \\
\hline Low birth weight: yes & 1.00 & ref & 1.22 & $0.71-2.10$ & 0.4678 & 2.68 & $1.35-5.32$ & 0.0048 \\
\hline Prematurity: yes & 1.00 & ref & 1.23 & $0.75-2.02$ & 0.4050 & 2.00 & $1.01-3.98$ & 0.0470 \\
\hline Duration of breastfeeding (months) & 1.00 & ref & 1.46 & $1.20-1.77$ & 0.0001 & 1.49 & $1.07-2.06$ & 0.0168 \\
\hline Only child at the time of birth & 1.00 & ref & 1.29 & $1.02-1.64$ & 0.0350 & 1.47 & $1.00-2.19$ & 0.0524 \\
\hline Age of entry in school (years) & 1.00 & ref & 1.32 & $1.06-1.65$ & 0.0133 & 1.24 & $0.86-1.80$ & 0.2570 \\
\hline \multicolumn{9}{|l|}{ Parents' employment status } \\
\hline Mother working at 24 weeks of pregnancy & 1.00 & ref & 0.71 & $0.53-0.94$ & 0.0178 & 0.49 & $0.32-0.75$ & 0.0012 \\
\hline Mother working at 4 months after birth & 1.00 & ref & 1.01 & $0.80-1.27$ & 0.9209 & 0.89 & $0.60-1.31$ & 0.5458 \\
\hline Mother working at 8 months after birth & 1.00 & ref & 0.73 & $0.57-0.93$ & 0.0114 & 0.54 & $0.37-0.81$ & 0.0030 \\
\hline Mother working at 12 months & 1.00 & ref & 0.67 & $0.50-0.90$ & 0.0077 & 0.38 & $0.25-0.58$ & $<0.0001$ \\
\hline Mother working at 24 months & 1.00 & ref & 0.70 & $0.52-0.95$ & 0.0213 & 0.48 & $0.31-0.76$ & 0.0015 \\
\hline Father working at 24 weeks of pregnancy & 1.00 & ref & 1.26 & $0.65-1.61$ & 0.9037 & 1.39 & $0.34-1.22$ & 0.1805 \\
\hline Father working at 12 months & 1.00 & ref & 0.57 & $0.37-0.88$ & 0.0114 & 0.57 & $0.29-1.11$ & 0.1008 \\
\hline Father working at 24 months & 1.00 & ref & 0.66 & $0.44-1.00$ & 0.0513 & 0.56 & $0.30-1.06$ & 0.0757 \\
\hline \multicolumn{9}{|l|}{ Single parent status } \\
\hline At 24 weeks of pregnancy & 1.00 & ref & 1.52 & $1.01-2.27$ & 0.0427 & 1.78 & $0.97-3.29$ & 0.0641 \\
\hline At 4 months after birth & 1.00 & ref & 1.40 & $0.74-2.62$ & 0.3002 & 1.44 & $0.53-3.91$ & 0.4798 \\
\hline At 8 months after birth & 1.00 & ref & 1.45 & $0.80-2.64$ & 0.2181 & 1.58 & $0.62-3.98$ & 0.3365 \\
\hline At 12 months after birth & 1.00 & ref & 1.14 & $0.62-2.11$ & 0.6730 & 0.98 & $0.33-2.89$ & 0.9718 \\
\hline At 24 months after birth & 1.00 & ref & 1.12 & $0.64-1.95$ & 0.6976 & 1.65 & $0.74-3.68$ & 0.2199 \\
\hline \multicolumn{9}{|l|}{ Parents' education level $\mathbb{I I}$} \\
\hline Mother with higher education & 1.00 & ref & 0.54 & $0.43-0.67$ & $<0.0001$ & 0.47 & $0.32-0.68$ & $<0.0001$ \\
\hline Father with higher education & 1.00 & ref & 0.60 & $0.49-0.74$ & $<0.0001$ & 0.49 & $0.33-0.72$ & 0.0002 \\
\hline \multicolumn{9}{|l|}{ Financial difficulties } \\
\hline 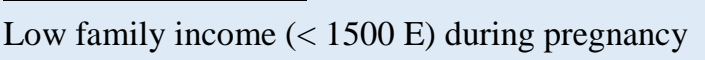 & 1.00 & ref & 1.68 & $0.98-2.88$ & 0.0599 & 2.40 & $1.10-5.23$ & 0.0274 \\
\hline$>=1$ financial difficulty during pregnancy & 1.00 & ref & 1.42 & $1.14-1.76$ & 0.0020 & 1.91 & $1.31-2.79$ & 0.0008 \\
\hline Low family income $(<1500 \mathrm{E})$ during 1 st year & 1.00 & ref & 1.83 & $1.43-2.35$ & $<0.0001$ & 2.45 & $1.66-3.62$ & $<0.0001$ \\
\hline$>=1$ financial difficulty felt in 1 st year & 1.00 & ref & 1.58 & $1.14-2.19$ & 0.0057 & 2.40 & $1.50-3.84$ & 0.0003 \\
\hline Low family income $(<1500 \mathrm{E})$ during 2 nd year & 1.00 & ref & 1.41 & $1.13-1.76$ & 0.0027 & 2.60 & $1.72-3.93$ & $<0.0001$ \\
\hline
\end{tabular}




\begin{tabular}{|c|c|c|c|c|c|c|c|c|}
\hline$>=1$ financial difficulty during 2 nd year & 1.00 & ref & 1.55 & $1.10-2.19$ & 0.0131 & 2.96 & $1.84-4.75$ & $<0.0001$ \\
\hline \multicolumn{9}{|l|}{ Substance use } \\
\hline Maternal cannabis use prior to pregnancy & 1.00 & ref & 1.16 & $0.72-1.89$ & 0.5411 & 1.81 & $0.91-3.61$ & 0.0918 \\
\hline Maternal tobacco use prior to pregnancy & 1.00 & ref & 1.13 & $1.05-1.67$ & 0.0194 & 1.22 & $0.99-2.15$ & 0.0550 \\
\hline Maternal tobacco use during pregnancy & 1.00 & ref & 1.59 & $1.22-2.07$ & 0.0005 & 1.65 & $1.08-2.52$ & 0.0205 \\
\hline Maternal alcohol use during pregnancy & 1.00 & ref & 1.03 & $0.80-1.32$ & 0.8220 & 1.01 & $0.66-1.53$ & 0.9731 \\
\hline Paternal alcohol problem & 1.00 & ref & 1.78 & $1.08-2.93$ & 0.0242 & 1.94 & $0.91-4.17$ & 0.0871 \\
\hline \multicolumn{9}{|l|}{ Parents' childhood problems } \\
\hline Maternal childhood adversity & 1.00 & ref & 1.43 & $1.12-1.83$ & 0.0048 & 1.92 & $1.30-2.84$ & 0.0011 \\
\hline Maternal childhood speech delay & 1.00 & ref & 1.78 & $1.31-2.43$ & 0.0003 & 2.57 & $1.63-4.05$ & $<0.0001$ \\
\hline Maternal childhood behavior problems & 1.00 & ref & 1.12 & $0.69-1.81$ & 0.6400 & 3.02 & $1.67-5.45$ & 0.0002 \\
\hline Paternal childhood behavior problems & 1.00 & ref & 1.57 & $1.07-2.32$ & 0.0219 & 2.69 & $1.62-4.49$ & 0.0001 \\
\hline Paternal childhood speech delay & 1.00 & ref & 1.56 & $1.22-1.99$ & 0.0004 & 2.07 & $1.40-3.05$ & 0.0003 \\
\hline \multicolumn{9}{|l|}{ Child's activities with the parents } \\
\hline Mostly the mother: 4 and 8 months & 1.00 & ref & 1.19 & $0.93-1.53$ & 0.1690 & 0.77 & $0.49-1.23$ & 0.2731 \\
\hline Mother $>5$ days/week : at 12 months & 1.00 & ref & 0.72 & $0.56-0.92$ & 0.0078 & 0.94 & $0.62-1.40$ & 0.7462 \\
\hline Father $>5$ days/week : at 12 months & 1.00 & ref & 0.67 & $0.51-0.89$ & 0.0050 & 0.84 & $0.53-1.33$ & 0.4531 \\
\hline Mother $>5$ days/week : at 24 months & 1.00 & ref & 0.65 & $0.41-1.03$ & 0.0646 & 0.76 & $0.37-1.55$ & 0.4466 \\
\hline Father $>5$ days/week : at 24 months & 1.00 & ref & 0.80 & $0.62-1.05$ & 0.1035 & 0.88 & $0.57-1.37$ & 0.5749 \\
\hline \multicolumn{9}{|l|}{ Mother's psychological status } \\
\hline Depression during pregnancy (CESD) $¥$ & 1.00 & ref & 1.36 & $0.89-2.07$ & 0.1576 & 2.15 & $1.17-3.94$ & 0.0133 \\
\hline Depression at 4 months (EPDS) $\S$ & 1.00 & ref & 1.37 & $0.88-2.12$ & 0.1639 & 3.14 & $1.60-6.20$ & 0.0013 \\
\hline Depression at 8 months (EPDS) $\S$ & 1.00 & ref & 1.84 & $1.22-2.78$ & 0.0041 & 3.77 & $2.02-7.05$ & $<0.0001$ \\
\hline Depression at 12 months (EPDS) $\S$ & 1.00 & ref & 1.67 & $1.14-2.43$ & 0.0084 & 2.28 & $1.34-3.88$ & 0.0025 \\
\hline Psychological help during pregnancy & 1.00 & ref & 1.03 & $0.74-1.42$ & 0.8846 & 1.23 & $0.73-2.07$ & 0.4469 \\
\hline Psychological help at 4 months & 1.00 & ref & 1.13 & $0.70-1.83$ & 0.6069 & 1.92 & $0.99-3.71$ & 0.0521 \\
\hline Psychological help at 8 months & 1.00 & ref & 0.93 & $0.60-1.45$ & 0.7581 & 1.53 & $0.82-2.87$ & 0.1776 \\
\hline Psychological help at 12 months & 1.00 & ref & 1.27 & $0.85-1.92$ & 0.2464 & 2.21 & $1.26-3.88$ & 0.0059 \\
\hline Psychological help at 24 months & 1.00 & ref & 1.00 & $0.69-1.44$ & 0.9954 & 1.41 & $0.81-2.44$ & 0.2252 \\
\hline History of mental health problems & 1.00 & ref & 1.43 & $1.03-1.98$ & 0.0338 & 2.71 & $1.72-4.27$ & $<0.0001$ \\
\hline Absence of social support & 1.00 & ref & 0.86 & $0.67-1.10$ & 0.2263 & 0.77 & $0.51-1.14$ & 0.1907 \\
\hline
\end{tabular}

If BAC or Baccalauréat in France is equivalent to Higher School Certificate- or Matura in other European countries

$¥$ CES-D: Center of Epidemiological Studies Depression scale (depression $=$ CESD score $>=23$ )

$\S$ EPDS: Edinburg Postnatal Depression Scale (depression $=$ EPDS score $>=13$ )

ref $=$ reference

Supplementary Table 2: Key confounders after Inverse Probability Weights are applied.

\begin{tabular}{|l|c|c|c|c|}
\hline Variables & $\begin{array}{c}\text { Child- } \\
\text { minder }\end{array}$ & $\begin{array}{c}\text { Center-based } \\
\text { childcare }\end{array}$ & $\begin{array}{c}\text { Informal } \\
\text { childcare }\end{array}$ & $p$ \\
\hline Center of birth & \multicolumn{3}{|c|}{0.0114} \\
\hline
\end{tabular}




\begin{tabular}{|lcccc|}
\hline Nancy & 49.1 & 55.7 & 48.4 & \\
Poitiers & 50.9 & 44.3 & 51.6 & \\
Gender & & & & $\mathbf{0 . 7 2 1 5}$ \\
Female & 47.9 & 48.2 & 48.3 & \\
Male & 52.1 & 51.8 & 51.7 & \\
Prematurity & 4.4 & 6.0 & 3.9 & $\mathbf{0 . 2 0 5 0}$ \\
Mother working at 24 weeks of pregnancy & 85.8 & 80.1 & 83.5 & $\mathbf{0 . 0 1 2 6}$ \\
Mother working 4 months after birth & 47.0 & 40.0 & 47.4 & $<\mathbf{0 . 0 0 0 1}$ \\
Mother working 8 months after birth & 72.4 & 63.2 & 67.2 & $\mathbf{0 . 0 7 7 5}$ \\
Mother working at 12 months & 89.4 & 79.9 & 83.6 & $<\mathbf{0 . 0 0 0 1}$ \\
Father working at 24 weeks of pregnancy & 94.2 & 93.3 & 90.8 & $<\mathbf{0 . 0 0 0 1}$ \\
Mother with higher education & 61 & 56.7 & 58.8 & $\mathbf{0 . 0 5 6 8}$ \\
Father with higher education & 49 & 44.5 & 49.7 & $\mathbf{0 . 4 0 2 3}$ \\
>= financial difficulty during pregnancy & 51.5 & 56 & 55.9 & $<\mathbf{0 . 0 0 0 1}$ \\
>= financial difficulty felt in 1st year & 29.2 & 32.8 & 37.4 & $<\mathbf{0 . 0 0 0 1}$ \\
>= financial difficulty during 2nd year & 55.1 & 57.9 & 57.1 & $\mathbf{0 . 0 6 8 6}$ \\
Maternal tobacco use during pregnancy & 25.6 & 19.9 & 26.8 & $\mathbf{0 . 0 9 9 8}$ \\
Maternal childhood adversity & 25.2 & 32.7 & 30.0 & $<\mathbf{0 . 0 0 0 1}$ \\
Paternal childhood behavior problems & 11.7 & 11.6 & 11.0 & $\mathbf{0 . 3 1 7 8}$ \\
Paternal childhood speech delay & 26.6 & 35.0 & 28.3 & $\mathbf{0 . 0 6 8 8}$ \\
Depression during pregnancy (CESD) ¥ & 7.7 & 6.6 & 7.8 & $\mathbf{0 . 7 4 7 5}$ \\
Depression at 12 months (EPDS) § & 8.5 & 13.4 & 9.7 & $\mathbf{0 . 1 2 6 4}$ \\
Psychological help at 24 months & 14.2 & 11.9 & 13.6 & $\mathbf{0 . 5 0 6 0}$ \\
Absence of social support & 25.2 & 30.7 & 27.1 & $\mathbf{0 . 0 8 3 9}$ \\
\hline
\end{tabular}

